\title{
TRANSPLANTE DE MEDULA ÓSSEA EM PEDIATRIA E TRANSPLANTE DE CORDÃO UMBILICAL
}

\author{
BONE MARROW TRANSPLANTATION IN CHILDREN \\ AND CORD BLOOD TRANSPLANTATION
}

\author{
Luís Fernando S. Bouzas
}

Vice-Diretor do Centro de Transplante de Medula Óssea, Coordenador do Banco de Sangue de Cordão Umbilical e Placentário do Instituto Nacional do Câncer

CorRespondÊnCIA: Praça Cruz Vermelha 23 / $7^{0}$ andar - Centro- Rio de Janeiro - RJ CEP 20230-030

BOUZAS LFS. Transplante de medula óssea em pediatria e transplante de cordão umbilical. Medicina, Ribeirão Preto, 33: 241-263, jul./set. 2000.

RESUMO: O transplante de medula óssea tem sido utilizado em crianças, no tratamento de um crescente número de doenças hematológicas, malignas ou não, e nos tumores sólidos. A fonte de medula óssea, nesses casos, tem sido, na sua maioria, alogênica, incluindo doador relacionado HLA-idêntico; relacionado com um antígeno HLA diferente; não aparentados, HLAidênticos; ou, em raras circunstâncias, relacionado com dois ou três antígenos HLA diferentes. As células do sangue do cordão umbilical e placentário (SCUP) têm sido consideradas para transplante alogênico, aparentado ou não, com resultados promissores. A relativa facilidade de obtenção, a flexibilidade quanto à compatibilidade HLA entre pacientes e doadores e a possibilidade de armazenamento em bancos de células são alguns dos fatores que têm contribuído para 0 desenvolvimento da técnica. Os pacientes tratados com tumores sólidos recebem, em sua maioria, transplantes autogênicos de medula ou de células de sangue periférico. As complicações dos transplantes continuam a incluir a toxicidade precoce ou tardia dos regimes de condicionamento, doença de enxerto-contra-hospedeiro aguda e crônica, infecções, imunodeficiência prolongada e recidiva da doença de base. Com o aumento do tempo da sobrevida, principalmente na faixa etária pediátrica, existe uma grande preocupação com os efeitos colaterais tardios, que comprometem os resultados, no que diz respeito à qualidade de vida, alterações orgânicas debilitantes e distúrbios neuropsicossociais incapacitantes. As constantes pesquisas, desenvolvidas nessa área, continuarão a contribuir com métodos que diminuam as complicações pós-transplante, aumentando a sobrevida dos submetidos a transplantes, tanto de forma quantitativa, como qualitativa. lular.

UNITERMOS: Transplante de Medula Óssea. Cordão Umbilical. Pediatria. Transplante Ce(1).

\section{1- INTRODUÇÃO}

A reconstituição hematopoética, com transplante de medula óssea (TMO), é um tratamento já bem estabelecido para uma variedade de afecções hematológicas, oncológicas e imunológicas. Na primeira parte deste artigo de revisão, procuramos destacar, na população pediátrica, aspectos importantes do TMO, como indicações, regimes de condicio- namento mais adequados, complicações imediatas e tardias e fontes de obtenção da células tronco ou progenitoras hematopoéticas (CTH ou CPH), usadas, aqui, como sinônimas de hematopoetic stem cells. Na segunda parte, discutiremos aspectos teóricos e práticos do transplante de CTH, obtido do sangue de cordão umbilical e placentário (SCUP), destacando o estágio atual de desenvolvimento do procedimento no Brasil. 


\section{2- SELEÇÃO DE PACIENTES E DOADORES PARA O TMO PEDIÁTRICO}

Os pacientes considerados para transplante de medula óssea devem ter uma doença, na qual as opções de terapêutica convencional resultem em sobrevida livre de doença (SLD) nitidamente menor do que aquela esperada no transplante, consideradas as condições particulares do paciente. Na Tabela I, listamos várias doenças da população pediátrica, que preencham tal critério, incluindo malignidades hematológicas em primeira ou segunda remissão ou em fase crônica de leucemia mielóide, crônica, com cromossoma Philadelphia (Ph1) positivo e crianças com linfomas em segunda remissão ou com estágio IV de tumores sólidos em boa remissão parcial, isto é, com reduzida massa tumoral e favorável condição clínica.

Os pacientes devem ter uma fonte adequada de "stem cells" (CTH) provenientes, se possível, de um doador HLA-compatível. As opções para doador alogênico são: 1) membros da família idênticos para os antígenos de histocompatibilidade leucocitária (HLA) ou com um único antígeno HLA diferente do do paciente; 2) indivíduos não aparentados HLA- idênticos ou com um antígeno diferente do do paciente; 3 ) membros da família com dois ou três antígenos diferentes, estando o paciente em remissão.
As fontes de células progenitoras hematopoéticas, presentemente utilizadas para transplante, são a medula óssea (MO), as células progenitoras de sangue periférico (CPSP) ou o sangue do cordão umbilical e placentário (SCUP) de um doador aparentado ou não aparentado $^{(1 / 5)}$.

Em geral, os pacientes com tumores sólidos recebem transplantes autogênicos, usando, tanto MO, quanto, mais recentemente, CPSP. A medula óssea alogênica e o SCUP são, geralmente, usados para pacientes com malignidades hematológicas. Apesar das dificuldades com o acesso venoso, é possível a obtenção de CPSPs de doadores normais acima de 12 anos e autogênicas de pacientes com $10 \mathrm{~kg}$ ou mais ${ }^{(4-6)}$. A utilização de células de SCUP será abordada na segunda parte desta revisão.

Em 1996, Schmitz et al. publicaram um artigo, resumindo a prática dos transplantes de células tronco hematopoéticas na Europa ${ }^{(7)} \mathrm{e}$, em 1998, Goldman et al. atualizaram os dados, introduzindo modificações, principalmente nas categorias onde se alocavam os diferentes procedimentos de transplante e as principais diferenças entre crianças e adultos ${ }^{(8)}$. Os procedimentos foram classificados em: 1 . Rotina (R): transplantes realizados nos principais centros da Europa, sem necessidade de os pacientes estarem incluídos em protocolos de estudo, com resultados bem definidos e

\begin{tabular}{|c|c|c|c|c|c|}
\hline Diagnóstico & Fase & $\begin{array}{c}H L A=\text { ou } 1 \\
A g \#\end{array}$ & $\begin{array}{c}\text { Não } \\
\text { aparentado }\end{array}$ & $\begin{array}{l}2 \text { ou } 3 \mathrm{Ag} \# \\
\text { aparentado }\end{array}$ & Autogênico \\
\hline $\begin{array}{l}\text { Leucemia linfóide } \\
\text { aguda }\end{array}$ & $\begin{array}{l}\mathrm{RC} 1 / \mathrm{RC} 2 ; \geq \mathrm{RC} 3 \\
\text { Recaída }\end{array}$ & $\begin{array}{l}+ \\
+ \\
+\end{array}$ & $\begin{array}{l}+ \\
+ \\
--\end{array}$ & $\begin{array}{l}-- \\
+ \\
+\end{array}$ & $\begin{array}{l}+ \\
-- \\
--\end{array}$ \\
\hline $\begin{array}{l}\text { Leucemia mielóide } \\
\text { aguda }\end{array}$ & $\begin{array}{l}\text { RC1; } \\
\text { RC2; } \\
\text { Recaída }\end{array}$ & $\begin{array}{l}+ \\
+ \\
+\end{array}$ & $\begin{array}{l} \pm \\
+ \\
--\end{array}$ & $\begin{array}{l}-- \\
+ \\
+\end{array}$ & $\begin{array}{l}+ \\
-- \\
--\end{array}$ \\
\hline $\begin{array}{l}\text { Leucemia mielóide } \\
\text { crônica }\end{array}$ & $\begin{array}{l}\text { Adulta; } \\
\text { Juvenil }\end{array}$ & $\begin{array}{l}+ \\
+ \\
\end{array}$ & $\begin{array}{l}+ \\
+ \\
\end{array}$ & $\begin{array}{l}-- \\
+ \\
\end{array}$ & -- \\
\hline Neuroblastoma & $\begin{array}{l}\text { RC1; RC2 } \\
\text { RP muito boa* }\end{array}$ & $\begin{array}{l}+ \\
+ \\
\end{array}$ & $\begin{array}{l}-- \\
--\end{array}$ & -- & $\begin{array}{l}+ \\
+ \\
\end{array}$ \\
\hline Sarcoma de Ewing & $\begin{array}{l}\mathrm{RC} 1 ; \mathrm{RC} 2 \\
\mathrm{RP} \text { muito boa }\end{array}$ & -- & -- & -- & $\begin{array}{l}+ \\
+ \\
\end{array}$ \\
\hline $\begin{array}{l}\text { Tumor } \\
\text { Cerebral }\end{array}$ & $\begin{array}{l}\mathrm{RC} 2 \\
\mathrm{RP} \text { muito boa }\end{array}$ & $\begin{array}{l}-- \\
--\end{array}$ & $\begin{array}{l}-- \\
--\end{array}$ & $\begin{array}{l}-- \\
--\end{array}$ & $\begin{array}{l}+ \\
+\end{array}$ \\
\hline
\end{tabular}


comparáveis ou superiores às estratégias de tratamento sem transplante; 2. Protocolo de Pesquisa Clínica (PPC): o valor do transplante para esta categoria não está claramente estabelecido, porém, pacientes podem ser incluídos no contexto de estudos clínicos, aprovados nas diferentes instituições e com o compromisso de apresentação ou publicação dos resultados para a comunidade médica; 3. Desenvolvimento (D): são assim classificados, se existe pouca ou nenhuma experiência nacional ou internacional com este tipo particular de transplante, em geral, envolvendo casos isolados ou pequenas séries-piloto de pacientes com afecções de interesse particular em unidades; especializadas; 4. Geralmente Não Recomendado (NR): nesta categoria incluem-se procedimentos para doenças em cuja fase ou status não há indicação de transplante de células hematopoéticas. Na Tabela II, está resumida a proposta do trabalho de classificação dos procedimentos de TMO para crianças.

Em outubro de 1999, após reuniões de consenso dos membros dos principais centros de transplante no Brasil e, com base no citado estudo do grupo europeu, a Sociedade de Brasileira de Transplante de Medula Óssea (SBTMO) e o Ministério da Saúde oficializaram, também para o nosso país, as mesmas categorias, derivadas, em grande parte, da experiência européia (Tabela III). Desta forma, constituiu-se a primeira regulamentação nacional para a utilização dos procedimentos de transplante de CTH. Apesar de não serem destacadas em uma categoria separada, na Portaria, as indicações do transplante de CTH pediátrico seguem os princípios contidos na Tabela II e as indicações para adultos, isto é, o transplante é recomendado em doenças e estádios onde ele produz melhores resultados, comparado com a terapêutica convencional.

\section{3- REGIMES DE CONDICIONAMENTO PARA O TMO PEDIÁTRICO}

Os pacientes são preparados para o transplante de medula óssea com combinação de altas doses de agentes quimioterápicos, associados ou não com radioterapia, a fim de eliminar células malignas ativas e residuais. Esses regimes de condicionamento são bastante intensos, produzindo, portanto, toxicidade hematopoética significativa. Quando o doador é alogênico, o regime deve, também, promover imunossupressão adequada, para permitir a "pega do enxerto". Alguns exemplos estão citados na Tabela $\operatorname{IV}^{(6,9 / 15)}$.

\section{4- DOENÇA DO ENXERTO-CONTRA-HOS- PEDEIRO}

Todos os pacientes que recebem medula óssea, CPSP ou sangue de cordão umbilical alogênicos estão, sob risco de desenvolver a doença do enxertocontra-hospedeiro (DECH) após a pega do enxerto ${ }^{(1,5,16)}$ (vide capítulo IV). Essa reação imunológica é mediada por células imunocompetentes, particularmente linfócitos $\mathrm{T}$ maduros, presentes na medula ou no inóculo de células hematopoéticas do doador. Os receptores de medula óssea HLA-idêntica aparentada possuem menor risco de DECH (cerca de 20\%) e aqueles que recebem medula HLA-incompatível, aparentada ou medula não aparentada estão sob maior risco (cerca de 80\%).

De acordo com o período de instalação e tipo de sinais e sintomas, podemos classificar a DECH em aguda e crônica. Os principais órgãos acometidos na DECH aguda são a pele, fígado e trato gastrintestinal. Já a DECH crônica é uma sindrome clínico-patológica que envolve vários orgãos e sistemas, assemelhandose muito às doenças auto-imunes ${ }^{(17)}$. Trata-se de uma complicação que compromete de forma significativa a sobrevida pós-TMO. As crianças abaixo de 10 anos de idade, que recebem enxertos HLA idênticos, têm uma incidência de DECH crônica de cerca de 13\%, enquanto que $30 \%$ das crianças de 10 a 19 anos desenvolvem a complicação. As crianças submetidas a TMO não aparentado apresentam uma incidência de DECH crônica de aproximadamente $40 \%^{(1,2)}$.

A principal estratégia desenvolvida contra o desenvolvimento da DECH no TMO é a profilaxia da forma aguda utilizando agentes imunossupressores em diferentes combinações ${ }^{(18 / 20)}$. Nos pacientes com a doença já instalada, o tratamento com intensa imunossupressão e modulação imunológica pode contribuir para uma melhor qualidade de sobrevida, porém sempre com elevado risco de complicações infecciosas que contribuem para a morbidade e mortalidade em tais casos. (Tabela V) ${ }^{(17,21)}$.

\section{5- TMO EM DOENÇAS PEDIÁTRICAS ESPE- CÍFICAS}

Nesta secção, abordaremos aspectos relativos às principais indicações de transplante de $\mathrm{CPH}$ em crianças, analisando os resultados de diferentes centros internacionais e a experiência do Centro de Transplante de Medula Óssea do Instituto Nacional de Câncer do Rio de Janeiro. 


\begin{tabular}{|c|c|c|c|c|}
\hline Diagnóstico & Estágio de doença & $\begin{array}{c}\text { Alogênico Doador } \\
\text { aparentado }\end{array}$ & $\begin{array}{c}\text { Alogênico Doador } \\
\text { alternativo }\end{array}$ & Autogênico \\
\hline \multirow[t]{3}{*}{ LMA } & $\mathrm{RC} 1$ (baixo risco) & NR & NR & NR \\
\hline & $\mathrm{RC} 1$ (alto risco) & $\mathrm{R}$ & NR & $\mathrm{R}$ \\
\hline & $\mathrm{RC2}$ & $\mathrm{R}$ & PPC & $\mathrm{R}$ \\
\hline \multirow[t]{3}{*}{ LLA } & $\mathrm{RC1}$ (baixo risco) & NR & NR & NR \\
\hline & $\mathrm{RC} 1$ (alto risco) & PPC & PPC & NR \\
\hline & RC2(ver texto) & $\mathrm{R}$ & $\mathrm{R}$ & PPC \\
\hline \multirow[t]{2}{*}{ LMC } & Fase crônica & $\mathrm{R}$ & $\mathrm{R}$ & PPC \\
\hline & Fase avançada & $\mathrm{R}$ & $\mathrm{R}$ & PPC \\
\hline \multirow[t]{3}{*}{ LNH } & $\mathrm{RC1}$ (baixo risco) & NR & NR & NR \\
\hline & $\mathrm{RC} 1$ (alto risco) & PPC & PPC & PPC \\
\hline & $\mathrm{RC} 2$ & $\mathrm{R}$ & PPC & PPC \\
\hline \multirow[t]{2}{*}{ D. Hodgkin } & $\mathrm{RC1}$ & NR & NR & NR \\
\hline & $1^{\text {a }}$ Recaída, RC2 & PPC & $\mathrm{D}$ & $\mathrm{R}$ \\
\hline SMD & (ver texto) & $\mathrm{R}$ & PPC & NR \\
\hline \multicolumn{2}{|l|}{ Imunodeficiência } & $\mathrm{R}$ & $\mathrm{R}$ & --- \\
\hline \multicolumn{2}{|l|}{ Talassemia } & $\mathrm{R}$ & NR & --- \\
\hline \multicolumn{2}{|l|}{ Anemia falciforme } & $\mathrm{R}$ & NR & --- \\
\hline \multicolumn{2}{|l|}{ Anemia aplástica } & $\mathrm{R}$ & PPC & --- \\
\hline \multicolumn{2}{|l|}{ Sindr. Blackfan-Diamond } & $\mathrm{R}$ & PPC & --- \\
\hline \multicolumn{2}{|l|}{$\begin{array}{l}\text { Erros Inatos do } \\
\text { Metabolismo }\end{array}$} & PPC & PPC & --- \\
\hline \multirow[t]{7}{*}{ Tumores Sólidos } & Tumor de céls. germinativas & NR & NR & PPC \\
\hline & Sarcoma de Ewing & NR & NR & PPC \\
\hline & Sarcoma de partes moles & NR & NR & PPC \\
\hline & Neuroblastoma & NR & NR & PPC \\
\hline & Tumor de Wilms & NR & NR & PPC \\
\hline & Sarcoma osteogênico & NR & NR & $\mathrm{D}$ \\
\hline & Tumores cerebrais & NR & NR & PPC \\
\hline \multicolumn{2}{|l|}{ Doenças autoimunes } & NR & NR & $\mathrm{D}$ \\
\hline
\end{tabular}


Tabela III - Regulamentação da indicação do transplante de células tronco hematopoéticas no Brasil ${ }^{\star}$

1 Transplantes autogênicos não experimentais (idade $<60$ anos, excetuando o MM)

A- Leucemia mielóide aguda em $1^{\mathrm{a}}$ ou $2^{\mathrm{a}}$ remissão

B- Lifoma não-Hodgkin agressivo em $1^{\text {a }}$ recidiva quimiossensível

C- Doença de Hodgkin como terapia de salvamento (excluindo pacientes que falharam a >2 esquemas terapêuticos)

D- Mieloma múltiplo (idade $<65$ anos)

F- Tumores germinativos em recidiva, sensíveis aos tratamentos convencionais

E- Neuroblastoma de mau prognóstico em $1^{a}$ remissão

2 Transplantes alogênicos aparentados (<55 anos)

A- Leucemia mielóide aguda em $1^{a}$ remissão, exceto M3 (forma promielocítica)

B- Leucemia mielóide aguda em $2^{\mathrm{a}}$ ou $3^{\mathrm{a}}$ remissão ou em $1^{\mathrm{a}}$ recidiva

C- Leucemia linfóide aguda ou linfoma linfoblástico em $2^{a}$ remissão

D- Leucemia linfóide aguda em $1^{\text {a }}$ recidiva

E- Leucemia linfóide aguda $\mathrm{Ph} 1+$ em $1^{\mathrm{a}}$ ou $2^{\mathrm{a}}$ remissão

F- Leucemia mielóide crônica em fase crônica ou acelerada

G- Anemia aplástica grave

3 Transplantes alogênicos não-aparentados

A- Leucemia mielóide crônica em fase crônica (até 50 anos de idade)

B- Anemia refratária com excesso de blastos (até 45 anos de idade)

4 Transplante de células progenitoras do sangue periférico

A- Mesmas indicações e limite de idade do item 2, com exceção da anemia aplástica grave

5 Transplante de cordão umbilical

A- Mesmas indicações do item 2 (para adultos) ou da Tabela II (para crianças), com as seguintes condições: receptor com peso de até $50 \mathrm{~kg}$ e compatibilidade HLA completa na classe II (loco DRB1) e, no máximo, dois antígenos diferentes na classe I (HLA-A e -B). Estas indicações serão regulamentadas no futuro em separado.

6 Outras indicações

A- Indicações de transplante em síndromes mielodisplásticas, doenças hereditárias e imunodeficiências primárias, assim como em casos duvidosos ou em protocolos investigacionais, dependerão da aprovação de uma Comissão técnica integrada por representantes do INCA, da Sociedade Brasileira do TMO e do Ministério da Saúde. Os protocolos de investigação deverão ainda ser aprovados por Comissão de Ética em Pesquisa institucional vinculada ao Conselho Nacional de Ética em Pesquisa (CONEP).

* Portaria No 1.217/GM de 13/10/1999 do Ministério da Saúde.

\section{Tabela IV - Regimes de Condicionamento para TMO pediátrico}

AGENTE QUIMIOTERÁPICO

$\mathrm{CY}, 120 \mathrm{mg} / \mathrm{kg}$

Ara C, $36 \mathrm{~g} / \mathrm{m}^{2}$

Ara C, $6-36 \mathrm{~g} / \mathrm{m}^{2}+\mathrm{CY}, 60-120 \mathrm{mg} / \mathrm{kg}$

VP16, $60 \mathrm{mg} / \mathrm{kg}+\mathrm{CY}, 80-100 \mathrm{mg} / \mathrm{kg}$

VP16, $1800 \mathrm{mg} / \mathrm{m}^{2}+$ Tiotepa, $900 \mathrm{mg} / \mathrm{m}^{2}$

Melfalan, $110 \mathrm{mg} / \mathrm{m}^{2}$

Busulfan, $16 \mathrm{mg} / \mathrm{kg}+\mathrm{CY}, 120-200 \mathrm{mg} / \mathrm{kg}$
Irradiação corpórea total (Dose em Gy e tempo de fracionamento)

$12.0-15.75$ por $3-7$ dias

12.0 - por 3-6 dias

12.0 - por 3-6 dias

12.0 - por $3-6$ dias

12.0 - por $3-6$ dias

CY: ciclofosfamida; Ara-C: citosina arabinosina; VP16: etoposide. Adaptado de Sanders ${ }^{(21)}$ 


\begin{tabular}{|c|c|c|}
\hline & DECH Aguda & DECH Crônica \\
\hline \multirow[t]{7}{*}{ Prevenção } & MTX & Prevenção de DECH aguda \\
\hline & CSA & \\
\hline & $\mathrm{MTX}+\mathrm{CSA}$ & \\
\hline & $\mathrm{MTX}+\mathrm{CSA}+\mathrm{PDN}$ & \\
\hline & $\mathrm{CSA}+\mathrm{PDN}$ & \\
\hline & MTX +FK506 & \\
\hline & Depleção de células T & \\
\hline \multirow[t]{4}{*}{ Tratamento } & PDN & $P D N+C S A$ \\
\hline & Globulina antitimocítica & PDN + FK 506 \\
\hline & FK 506 & Azatioprina \\
\hline & PUVA & PUVA \\
\hline
\end{tabular}

\subsection{Leucemia Linfoblástica Aguda}

Anualmente, aproximadamente 1200 crianças com menos de 15 anos de idade são diagnosticadas com leucemia linfoblástica aguda (LLA), nos EUA. Os resultados atuais com quimioterapia mostram cerca de $70 \%$ das crianças obtendo sobrevida livre de doença (SLD) ${ }^{(22)}$, contudo, aquelas que recaem continuam a apresentar SLD pobre a longo prazo. As crianças com alto risco de recaída durante a remissão inicial são aquelas com LLA-T, com menos de 12 meses de idade ao diagnóstico, que apresentam anormalidades citogenéticas, incluindo hiplodiploidia $(<45$ cromossomos), translocações 4-11 ou 9-22, que falharam ao entrar em remissão dentro de 28 dias após o ínicio da indução, e aquelas com contagem inicial de leucócitos superior a $100 \mathrm{ml} / \mathrm{mm}^{3}$. A quimioterapia convencional, nos casos que recidivam, resulta em menos do que $30 \%$ de SLD, enquanto o TMO resulta em 67 a $80 \%$ de $\operatorname{SLD}^{(23 / 25)}$.

O TMO, na maioria dos casos, é considerado quando o paciente com LLA atinge a segunda remissão após recaída. As crianças que recaem durante a quimioterapia têm menos que $10 \%$ de SLD e aquelas que recaem com mais de um ano sem tratamento têm $30 \%$ de SLD. Os pacientes que recebem transplante de um doador HLA idêntico, aparentado ou não, têm SLD de 40 a $60 \%$. (Tabela VI) ${ }^{(2,3,12,26 / 29)}$.

Em resumo, pacientes selecionados com mau prognóstico são considerados para TMO alogênico em primeira remissão (RC1) se tiverem um doador aparentado HLA idêntico ou, em alguns centros, um doador não aparentado. Os transplantes autogênicos não são recomendados devido à alta freqüência de recaídas. A situação em pacientes em segunda remissão (RC2) é mais complicada. As crianças que recaem muito precocemente (por exemplo, durante o primeiro ano de tratamento) ou que sofrem de LLA-T não têm chance de cura com quimioterapia convencional. Portanto, nestas situações, o TMO alogênico, aparentado ou não, é indicado. Em recaídas mais tardias da doença, pode-se recomendar o auto-TMO em $2^{\text {a }}$ remissão dentro de protocolos de pesquisa ${ }^{(6,13,22,30)}$

Atualmente, o maior problema para crianças submetidas ao transplante de células tronco hematopoéticas é a recidiva leucêmica. Alguns investigadores estão analisando o uso de agentes biológicos, como os interferons e a interleucina-2, bem como o uso de infusões de linfócitos do doador após transplantes alogênicos e, entre os receptores de transplantes autogênicos, além destes agentes, métodos de eliminação de células residuais no inóculo e o desenvolvimento de regimes preparativos mais eficazes ${ }^{(21)}$.

\subsection{Leucemia Mielóide, Aguda (LMA)}

Os atuais regimes de quimioterapia resultam em taxas de indução inicial de 70 a $75 \%$ para pacientes recém-diagnosticados com LMA e, destes, cerca de 30 a $45 \%$ sobrevivem em remissão contínua. Estudos 


\begin{tabular}{|lccccc|}
\hline \multicolumn{7}{|l}{ Tabela VI - Resultados do TMO em leucemias agudas na infância } & & \\
\hline \multicolumn{1}{|c}{ Centro/ Diagnóstico } & Pacientes & \multicolumn{1}{c}{ Doador } & $\begin{array}{c}\text { Processamento } \\
\text { da medula }\end{array}$ & $\begin{array}{c}\text { Recaída } \\
(\%)\end{array}$ & $\begin{array}{c}\text { SLD } \\
(\%)\end{array}$ \\
\hline MSK / LLA & 31 & Idêntico aparentado & --- & 13 & 64 \\
\hline Seattle / LLA & 57 & Idêntico aparentado & --- & 42 & 58 \\
Seattle / LMA & 38 & & --- & 20 & 64 \\
\hline IBMTR / LLA & 255 & Idêntico aparentado & --- & 45 & 40 \\
\hline Minnesota / LMA & 73 & Idêntico aparentado & --- & ND & 61 \\
\hline POG / LMA & 89 & Idêntico aparentado & --- & ND & 58 \\
\hline Minnesota / LLA & 155 & Autogênico & AcM & ND & 17 \\
\hline EORTC / LLA & 83 & Autogênico & Drogas & ND & 33 \\
\hline Seattle / LMA & 13 & Autogênico & --- & 67 & 22 \\
\hline POG / LMA & 115 & Autogênico & Perfosfamida & ND & 38 \\
\hline
\end{tabular}

SLD - sobrevida livre de doenca; MSK - Memorial Sloan-Ketterina Cancer Center; Seattle - Fred Hutchinson Research Center: IBMTR - reaistro internacional de TMO; POG - Pediatric Oncoloav Group; EORTIC - European Organization for Research and Treatment of Cancer; AcM - anticorpo monoclonal. Adaptada da ref. 21

prospectivos, comparando a evolução de pacientes com doadores aparentados HLA idênticos e aqueles que continuaram recebendo quimioterapia, demonstraram SLD superior para aqueles que receberam um TMO em RC1 (50 a 65\%) comparado com quimioterapia (35 a 45\%) em cinco anos. Recentemente sugeriu-se que a intensidade do regime de indução de remissão é importante na evolução subseqüente pós-TMO alogênico. Os resultados de alguns estudos em LMA estão listados na Tabela VI. Os regimes de condicionamento com irradiação corpórea total (ICT) ou quimioterapia sem ICT ${ }^{(31)}$ são comparáveis e a escolha deve ser baseada na capacidade de cada centro. Para os pacientes que não possuem um doador HLA idêntico familiar, pode-se utilizar doadores não aparentados ou medula autogênica. Em geral, doadores não aparentados são utilizados para pacientes com doença avançada (>RC1). A questão se o transplante de células progenitoras hematopoéticas alogênicas alcança melhores resultados do que o transplante autogênico ainda permanece indefinida. Em segunda remissão, os resultados de quimioterapia são piores do que o de transplante, justificando a recomendação de todos os tipos de transplante de $\mathrm{CPH}$ em $\mathrm{RC} 2^{(8,32 / 35)}$.

\subsection{Leucemia Mieloide Crônica (LMC)}

O transplante de $\mathrm{CTH}$ é um tratamento eficaz para $\mathrm{LMC}^{(36)}$. Embora a maioria dos pacientes alcance uma remissão hematológica e citogenética completa, com o regime de condicionamento, a SLD depende da fase da doença no momento do transplante. Os pacientes tratados em crise blástica têm $10 \%$ a $20 \%$ de SLD, aqueles em fase acelerada têm 35 a $40 \%$ e os que estiverem em fase crônica atingem 50 a $80 \%$ de SLD. Quanto aos regimes de condicionamento utilizados, estudos demonstraram que a combinação de ciclofosfamida (120 mg/kg) e bussulfan (16mg/ $\mathrm{kg}$ ) é tão eficaz quanto a associação de ciclofosfamida e ICT com dose de $12.0 \mathrm{~Gy}^{(37)}$. Portanto, as recomendações para crianças com LMC Ph1 + são idênticas às dos adultos.

Os pacientes com LMC juvenil apresentam uma forma rara de doença mieloproliferativa, caracterizada por hepatoesplenomegalia, leucocitose, trombocitopenia e aumento da hemoglobina fetal. A doença ocorre em crianças com menos de cinco anos e não responde ao uso de quimioterapia convencional. $\mathrm{O}$ TMO alogênico resultou em SLD, em cinco anos, de cerca de $25 \%$ em Seattle e $31 \%$ na série de casos 
pediátricos do European Working Group on Mielodysplastic Syndrome ${ }^{(38)}$. A recaída pós-TMO é a maior causa de falha no tratamento, e agentes biológicos, como o ácido 13-cis-retinóico, têm sido utilizados no sentido de diminuir essa taxa.

\subsection{Síndrome Mielodisplástica (SMD)}

O transplante alogênico de $\mathrm{CPH}$ de um doador aparentado é o tratamento de escolha para crianças portadoras de síndromes mielodisplásticas do tipo padrão, leucemia mielomonocítica crônica, bem como LMA secundária ${ }^{(8,21)}$. Desde que as chances de cura com quimioterapia convencional são praticamente nulas, o transplante de CTH não aparentado pode também ser recomendado dentro de protocolos de pesquisa clínica. Permanece controversa a indicação de transplante autogênico em crianças e somente deve ser indicado nos casos de ausência de doadores idênticos, especialmente naquelas crianças com expectativa de entrar em remissão completa com relativa facilidade (ex. curto período de evolução e citogenética normal ou favorável).

\subsection{Anemia aplástica, aplasia pura de células vermelhas de Blackfan-Diamond e anemia de Fanconi ${ }^{(33,34)}$}

O transplante alogênico de $\mathrm{CPH}$ é o tratamento de escolha para crianças portadoras de anemia aplástica, grave, adquirida, que possuam um doador aparentado, HLA-idêntico ${ }^{(8,21)}$ (Vide Capítulo I). Para aqueles que não possuem este doador, está indicado um curso de tratamento intensivo imunossupressor (globulina antitimocítica e ciclosporina A), possivelmente associado ao fator de crescimento hematopoético
G-CSF. Para aqueles que falharam ao primeiro ciclo de imunossupressão, deve ser iniciada a busca de um doador não aparentado, enquanto recebem o segundo curso do tratamento. Caso seja identificado um doador, o paciente deve ser tratado dentro de um protocolo de pesquisa clínica.

As crianças com síndrome de BlackfanDiamond devem ser submetidas ao transplante, se não responderem aos corticosteróides ou se não se tornarem independentes de doses altas das drogas. Já os pacientes com anemia de Fanconi (AF), devem ser transplantados, se tiverem um doador HLA, idêntico, aparentado, sem alterações citogenéticas da doença. (vide Capítulo I). Aqueles que não possuem este doador podem ser tratados, utilizando-se um doador não aparentado, HLA idêntico ou SCUP, no contexto de um protocolo de pesquisa.

\subsection{Tumores Sólidos}

Em geral, o transplante alogênico de $\mathrm{CPH}$ não pode ser recomendado em crianças com tumores sólidos. Contudo, centros especializados poderão fazê-lo, tomando como base o desenvolvimento da técnica e de protocolos de pesquisa clínica. As crianças com tumores sólidos podem se beneficiar do transplante autogênico após altas doses de quimioterapia, nas situações listadas na Tabela VII.

O neuroblastoma, um tumor do sistema nervoso periférico, é o tumor sólido extra craniano mais comum na infância. Cerca de $60 \%$ dos pacientes diagnosticados apresentam tumores de alto risco e têm um prognóstico ruim, apesar da terapêutica agressiva convencional, com SLD inferior a 20\%. Durante a última década, quimioterapia combinada com ICT e infu-

Tabela VII - Indicações de TMO autogênico em crianças com tumores sólidos

\begin{tabular}{ll}
\hline Tipo de neoplasia & Estádio \\
\hline Tumores de células germinativas & Após recaída ou doença progressiva \\
Sarcoma de Ewing & Estágio IV e após recaída localizada. \\
Sarcomas de partes moles & Estágio IV ou após recidiva não ressecável. \\
Neuroblastoma & Estágio 4 em uma criança acima de 1 ano; estágios menos avançados com \\
& deleção de cromossoma 1p e/ou amplificação n-myc \\
Tumor de Wilms & Alto risco pela histologia ou recaída. \\
Sarcoma osteogênico & Embora o valor do transplante esteja indeterminado \\
Tumores cerebrais & Crianças com meduloblastoma e gliomas de alto grau responsivos a \\
& quimioterapia
\end{tabular}


são de medula autogênica "purgada" para pacientes em RC1 ou remissão parcial muito boa demonstraram uma SLD de 35 a $50 \%$ em cinco anos ${ }^{(14,15,21)}$. Em 1996, Odone et al. ${ }^{(39)}$ reportaram resultados preliminares do HCFMUSP-SP de 19 transplantes autogênicos e um singênico, em 13 crianças portadoras de neuroblastoma ou sete com outras neoplasias. Após cerca de um ano e meio de observação, a SLD era de $32 \%$. Os resultados de estudos prospectivos randomizados serão importantes no esclarecimento da superioridade ou não do transplante em relação à quimioterapia convencional, cirurgia e radioterapia localizada.

Os tumores do sistema nervoso central (SNC) compreendem o segundo maior grupo de neoplasias pediátricas, a maioria deles constituída de PNET (primitive neuroectodermal tumors), astrocitoma maligno e ependimoma. Apesar da cirurgia, radioterapia e quimioterapia convencional, a maior parte dos pacientes morre, como resultado de progressão ou recidiva do tumor. Alguns estudos relataram 20 a $26 \%$ de SLD em dois anos, utilizando quimioterapia com bussulfan, tiotepa e etoposide, seguido de medula óssea autogênica. Apesar dos resultados satisfatórios, ainda são necessários estudos com melhores métodos de controle da recidiva ${ }^{(10,40)}$.

\subsection{Outras indicações}

Podemos citar várias outras aplicações do transplante de $\mathrm{CPH}$ em crianças, incluindo linfomas malig- nos, síndromes de imunodeficiência, erros inatos do metabolismo, hemoglobinopatias e doenças auto-imunes. As considerações atuais sobre estas, e outras indicações estão na Tabela II.

\subsection{Resultados do CEMO/INCA com TMO pediátrico}

No período de novembro de 1984 a fevereiro de 2000, 139 pacientes na faixa etária de zero a 18 anos foram submetidos a 136 transplantes alogênicos de doadores aparentados HLA idênticos, e três autogênicos com medula óssea não "purgada", no Centro de Transplante de Medula Óssea do INCA-RJ. As indicações para o tratamento foram: anemia aplástica (42), anemia de Fanconi (4), LLA (24), LMA (34), LMC (16), SMD (13), DH (4) e outras (2). (Tabela VIII e Figura 1). Os regimes de condicionamento, profilaxia de DECH e terapêutica de suporte pós- transplante foram administrados de acordo com a literatura já citada e estabelecida. A sobrevida global foi de $47 \%$ com mediana de 1474 dias (variando de 01 a 4089), não sofrendo influência do sexo, idade ( $<$ ou > que 12 anos) ou do tipo de transplante.

As curvas de sobrevida (apresentadas na Figura 1) representam sobrevida global actuarial, total, a sobrevida em diferentes faixas etárias e a comparação entre afecções neoplásicas e não neoplásicas. De um modo geral, servem para demonstrar a reprodução, em nível nacional, de resultados obtidos em centros internacionais.

\begin{tabular}{|c|c|c|c|c|c|c|c|c|c|c|}
\hline \multirow{2}{*}{ Diagnóstico } & \multirow{2}{*}{$\begin{array}{c}\text { Transplantes } \\
\left(\mathrm{N}^{\circ}\right)\end{array}$} & \multicolumn{2}{|c|}{ Sexo } & \multicolumn{2}{|c|}{ Faixa Etária } & \multicolumn{2}{|c|}{ Óbitos } & \multicolumn{3}{|c|}{ Sobrevida Global (dias) } \\
\hline & & Masc. & Fem & $<12$ anos & $>12$ anos & $\mathrm{N}^{0}$ & $\%$ & mediana & média & $\mathrm{Dp}$ \\
\hline AAS & 42 & 23 & 19 & 15 & 27 & 19 & 45 & $>4089$ & 3046 & 391 \\
\hline LMA & 34 & 20 & 14 & 15 & 19 & 17 & 50 & 1139 & 2625 & 453 \\
\hline LLA & 24 & 13 & 11 & 15 & 9 & 17 & 71 & 498 & 1549 & 470 \\
\hline LMC & 16 & 3 & 13 & 10 & 6 & 7 & 44 & $>672$ & 2674 & 643 \\
\hline SMD & 13 & 8 & 5 & 9 & 4 & 8 & 62 & 687 & 1765 & 536 \\
\hline AF & 4 & 3 & 1 & 3 & 1 & 3 & 75 & 1238 & 1343 & 788 \\
\hline $\mathrm{DH}$ & 4 & 2 & 2 & 2 & 2 & 3 & 75 & 1488 & 1315 & 706 \\
\hline Outras & 2 & 2 & 0 & 2 & 0 & 0 & 0 & NA & 3532 & 0 \\
\hline Total & 139 & 74 & 65 & 71 & 68 & 74 & 100 & 1474 & 2521 & 218 \\
\hline
\end{tabular}



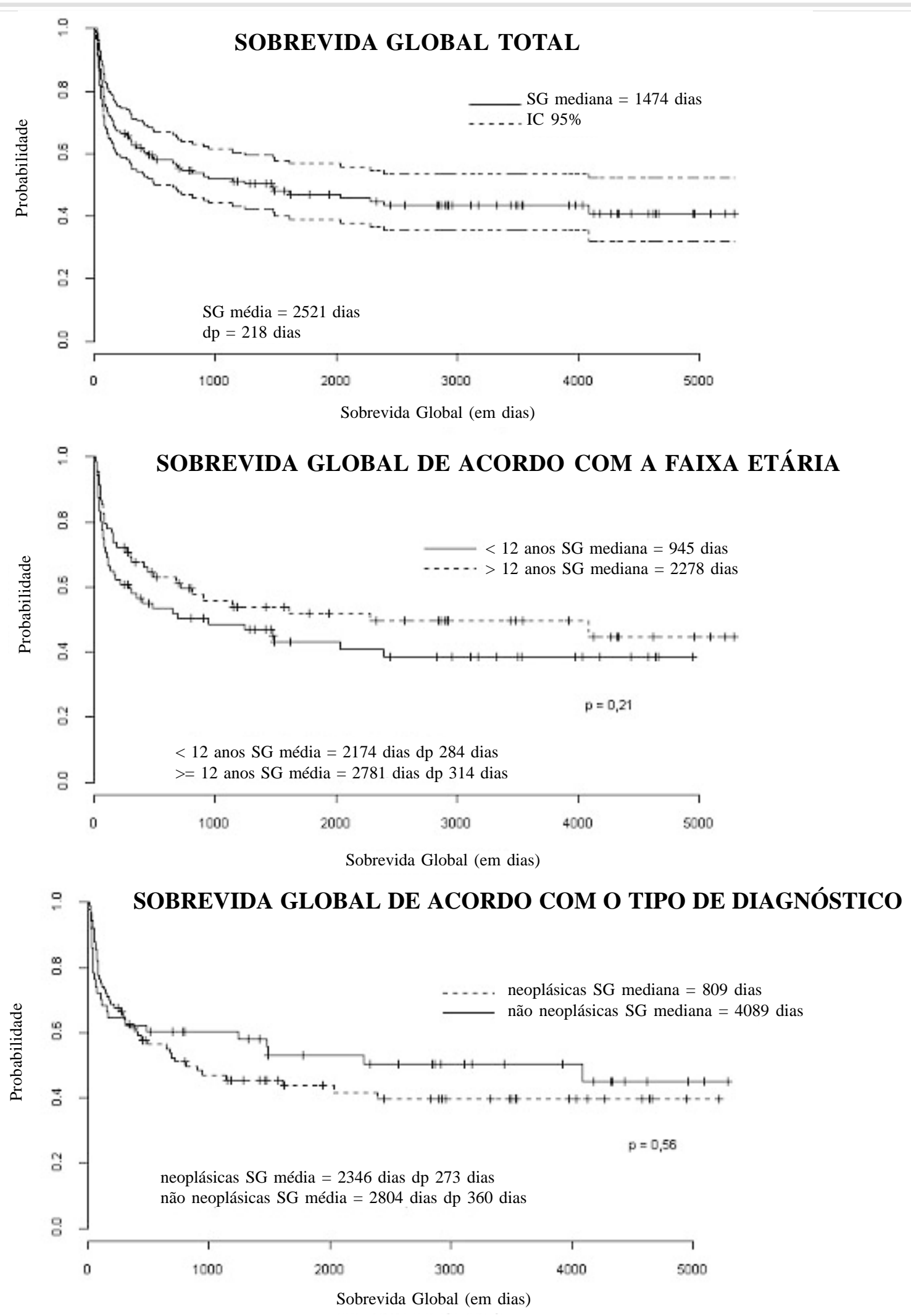

Figura 1 - Curvas atuariais de sobrevida global (SG) de crianças e adolescentes submetidos a transplante de medula óssea no Centro de Transplante de Medula Óssea do Instituto Nacional do Câncer do Rio de Janeiro no período de novembro de 1984 a fevereiro de 2000 . 


\subsection{Efeitos colaterais tardios do transplante}

Os efeitos tardios do TMO estão relacionados diretamente com o procedimento, com o regime de condicionamento ou com a doença de base do paciente. Eles estão listados na Tabela IX e serão tratados mais detalhadamente na $2^{\mathrm{a}}$ parte deste Simpósio.

\section{Tabela IX - Efeitos deletérios tardios do TMO \\ Relacionados ao procedimento \\ DECH crônica \\ Imunodeficiência \\ Desordens linfoproliferativas de células B \\ Rejeição do enxerto \\ Relacionados ao regime de condicionamento}

Disfunção pulmonar

Desordens oculares

Disfunção neuroendócrina

Desordem neuropsico-social

Malignidades Secundárias

Relacionados à doença de base do paciente

Recidiva de doença

\subsubsection{Disfunção Imunológica}

A disfunção imunológica pós-transplante é caracterizada pela falta de transferência sustentada de imunidade, clinicamente significativa, derivada de linfócitos $\mathrm{T}$ e $\mathrm{B}$, e distúrbios na ontogenia linfóide normal, efeitos operados em grande parte pela $\mathrm{DECH}$, principalmente crônica, e seu tratamento. A transferência de imunidade do doador para o receptor já está bem documentada e contribui para a recuperação da imunocompetência do paciente. A transferência de alguma imunidade mediada por linfócitos $\mathrm{T}$ foi demonstrada pela presença de títulos de anticorpos contra difteria, em receptores previamente negativos. A imunização com antígenos protéicos, imediatamente após o transplante, resulta no aumento de anticorpos de meia vida-curta $^{(41)}$. Contudo, a produção sustentada de anticorpos só ocorrerá quando houver recuperação ade- quada do número e função dos linfócitos T e B. Nos pacientes sem DECH crônica, a recuperação deverá ocorrer três a seis meses após o $\mathrm{TMO}^{(9)}$. Como a transferência de imunidade do doador é de curta duração, é recomendada a reimunização do receptor, iniciando-se um ano após o TMO, em geral, com a utilização de vacinas de vírus inativados, recombinantes ou com antígenos específicos (Tabela X), isto é, evitando-se o uso de vacinas com microorganismos vivos. Em pacientes portadores de DECH crônica ou usando imunossupressores por qualquer motivo, a imunização deve ser adiada por um ou dois anos, até haver evidência de algum grau de imunocompetência.

Tabela X - Esquema de imunização pós-TMO

\begin{tabular}{|ll|}
\hline Vacina & Tempo pós TMO \\
\hline Pólio Inativada (SALK) & 12 meses \\
Difteria / Tétano & 12 meses \\
Hepatite A & $1-2$ anos \\
Hepatite B & $1-2$ anos \\
Pneumocócica & $1-2$ anos \\
Haemophilus influenzae, tipo B & $1-2$ anos \\
MMR (sarampo,caxumba, & 2 anos \\
rubéola) & 2 anos \\
Varicela & 1 ano e anualmente \\
Influenza & \\
\hline
\end{tabular}

\subsubsection{Disfunção Pulmonar}

A doença pulmonar não tem sido bem estudada em crianças devido às dificuldades dos métodos de diagnóstico na população pediátrica, principalmente a broncoscopia, provas de função respiratória e a biópsia pulmonar. Em adultos, existe, geralmente, correlação entre o distúrbio restritivo pulmonar e o desenvolvimento de DECH crônica. Outro fator de significativa importância, no desenvolvimento de falência pulmonar tardia e morte (cerca de 10 a 15 anos após), seriam os efeitos tardios da ICT utilizada no regime de condicionamento ${ }^{(21)}$.

\subsubsection{Malignidades Secundárias}

Vários investigadores estão observando o desenvolvimento de malignidades secundárias entre aqueles pacientes com sobrevida longa pós-TMO ${ }^{(21)}$. Os da- 
dos do Registro Internacional de TMO (IBMTR) mostraram 109 malignidades secundárias em 10,000 pacientes, resultando numa incidência aproximada de 0.6/ 100 pacientes/ano, o que foi confirmado pelo grupo de Seattle entre 4294 sobreviventes do transplante. A análise de Seattle sugere que a probabilidade de desenvolver malignidade secundária 15 anos após TMO é de $6 \%$ nos pacientes, adultos e crianças, preparados sem ICT e $20 \%$ com ICT. Desta forma, torna-se mais uma vez importante a decisão de qual regime será aplicado ao paciente, principalmente na faixa etária pediátrica, a fim de minimizar o risco de malignidade tardia.

\subsubsection{Crescimento e Desenvolvimento}

Disfunção endócrina, levando a anormalidades do crescimento e desenvolvimento, tem sido descrita em várias séries de diferentes grupos de transplante. Com os regimes de condicionamento que incluem apenas ciclofosfamida, as crianças evoluem com função endócrina e desenvolvimento/crescimento normais. Por outro lado, regimes que incluem ICT levaram a 12 a $56 \%$ de disfunção tireoidiana, com o hormônio estimulador da tireóide (TSH) elevado e $13 \%$ com níveis subnormais de tiroxina, necessitando de suplementação hormonal ${ }^{(21)}$.

A deficiência de hormônio do crescimento (DHC) e a desaceleração concomitante nas taxas normais de crescimento foram observadas em aproximadamente 50 a $60 \%$ dos pacientes condicionados com ICT. Sem a reposição de hormônio do crescimento, a altura adulta final das crianças que estavam com menos de 11 anos no momento do transplante ficou abaixo do percentil 10. A reposição hormonal, no momento adequado, pode resultar em melhoria da altura adulta final. Essas observações foram reproduzidas em nossa casuística (Bordallo et al., comunicação pessoal), onde foi acrescentada a influência do uso prolongado de corticosteróides para tratamento de DECH, na patogênese dessas alterações.

Finalmente, todos os pacientes que receberam regimes com ICT ou bussulfan estão em risco de desenvolver disfunção gonadal. Os dados atuais apontam para um desenvolvimento puberal normal nas crianças que estavam com menos que 10 anos no momento do TMO. Contudo, pacientes com 10 anos ou mais desenvolvem insuficiência gonadal primária, com elevação dos níveis de hormônio luteinizante e de hormônio folículo-estimulante e, em meninas, redução dos níveis de estradiol. Em recente comunicação, Bordallo et al. ${ }^{(42)}$, relataram a evolução da puberdade e da função gonadal de 40 pacientes ( 23 do sexo masculino) submetidos a transplante alogênico, no período de 1984 a 1995. Com um acompanhamento médio de 5,25 \pm 2,7 anos, observaram que 13 pacientes apresentaram hipogonadismo hipergonadotrófico, sendo seis do sexo feminino, e que dois desses pacientes eram impúberes e 11 púberes, no momento do transplante. Concluíram, portanto, que a falência gonadal é mais freqüente nos pacientes que se encontram na puberdade na época do transplante e que o hipogonadismo tende a ser transitório no sexo feminino, já que $50 \%$ das pacientes recuperaram a função após reposição hormonal.

Segundo a experiência de Seattle, pacientes do sexo masculino, púberes não necessitam de reposição hormonal e cerca de $25 \%$ podem recuperar a função gonadal quatro a sete anos após receber ICT no regime de condicionamento ${ }^{(43)}$. Alguns desses pacientes podem demonstrar o retorno da fertilidade com gestações a termo. As pacientes do sexo feminino desenvolvem gestações de alto risco com elevada probabilidade de abortamento espontâneo, porém as crianças que nascem são normais. Relatamos, em $1999^{(44)}$ a evolução de 21 gestações em 16 pacientes submetidos a transplantes no CEMO/INCA, demonstrando que a possibilidade de gravidez é maior naquelas pacientes que receberam apenas regimes com ciclofosfamida ou com associação de agentes imunossupressores, em comparação com pacientes condicionados com ICT e bussulfan. Os dados sugerem que deve haver uma mudança efetiva na orientação das pacientes quanto à contracepção e comportamento sexual, já que existe, em alguns relatos, a possibilidade de gravidez.

\subsubsection{Recidiva de Doença Primária}

Os pacientes que apresentam recidiva de sua doença de base após o TMO podem ser submetidos a diferentes estratégias de resgate, dependendo do tempo pós-transplante em que ocorreu a recaída e do tipo de afecção primária. Para os pacientes que apresentam recidiva de tumores sólidos, não tem sido indicado um segundo transplante. Os pacientes com leucemias podem ser tratados com infusões de linfócitos do doador, com o objetivo de induzir remissão, estimulando o efeito enxerto-contra-leucemia. Os pacientes que mais se beneficiam com a estratégia são os portadores de LMC, seguidos daqueles com LMA, mas os resultados são ruins em LLA, com praticamente nenhum paciente apresentando resposta ${ }^{(21)}$.

Um segundo transplante de medula óssea pode ser realizado em alguns pacientes que recidivam, porém os resultados são comprometidos pela toxicidade dos regimes de condicionamento, principalmente quan- 
do realizado menos de 06 a 12 meses após o primeiro TMO. A SLD após um segundo TMO varia de 25 a $50 \%$, ocorrendo uma melhor resposta em crianças pela sua maior capacidade de tolerar a toxicidade dos regimes de condicionamento.

Estamos utilizando no CEMO/INCA, para os pacientes que recaem precocemente, um protocolo experimental de "mini-transplante" que emprega condicionamento quimioterápico menos intenso do que os convencionais (com $120 \mathrm{mg} / \mathrm{m}^{2}$ de fludarabina e 140 $\mathrm{mg} / \mathrm{m}^{2}$ de melfalan) e infusão de linfócitos do doador após o transplante, fim de estimular a resposta imunológica como principal mecanismo para a indução de remissão e sua manutenção. Os resultados de tal estudo ainda são preliminares, porém já demonstram tendências promissoras, como menor toxicidade precoce, rápida recuperação do paciente e possibilidade de utilização do regime mesmo com pouco tempo de recaída pós-TMO ${ }^{(45)}$.

\section{6- TRANSPlanTe DE CÉlulas PROGENI- TORAS HEMATOPOÉTICAS DE SANGUE DE CORDÃO UMBILICAL E PLACENTÁ- RIO (SCUP)}

\subsection{Introdução}

Como discutido acima e em outros capítulos deste Simpósio, o transplante alogênico de células progenitoras hematopoéticas $(\mathrm{CPH})$ tem sido utilizado, com sucesso, no tratamento de pacientes, adultos e crianças, com doenças hematológicas malignas, de alto risco ou recorrentes, síndromes de falência medular, estados selecionados de imunodeficiência e desordens metabólicas, causadas por erros inatos do metabolismo.

As principais limitações dos transplantes de medula óssea (TMO) alogênicos são a ausência de um doador compatível nos antígenos de histocompatibilidade leucocitários (HLA) e as complicações da doença do enxerto-contra-hospedeiro (DECH), que também estão associadas com disparidades no sistema HLA. Na ausência de um doador familiar HLA-idêntico, doadores alternativos, como familiares parcialmente compatíveis ou doadores voluntários, não-familiares, compatíveis podem ser usados ${ }^{(46)}$. Em tais transplantes, diferenças entre os antígenos maiores e menores de histocompatibilidade não são freqüentemente reconhecidas pelos testes de laboratório atualmente utilizados, mas são reconhecidas pelo sistema imunológico in vivo, explicando a freqüência eleva- da de complicações (DECH, falência do enxerto e retardo na recuperação imunológica). O desenvolvimento de testes mais sensíveis, como os moleculares, para a tipagem HLA, apesar de, potencialmente, reduzir as complicações imunológicas desse tipo de transplantes ${ }^{(47,48)}$, diminui também, a probabilidade de se encontrar um doador não relacionado plenamente compatível.

Apesar de existirem cerca de cinco milhões de doadores voluntários, cadastrados nos registros internacionais, $50 \%$ de todos os pacientes que necessitam um TMO continuam sem a possibilidade de encontrar um doador compatível. Além disto, pacientes de origem étnica e racial diferentes, do norte da Europa, apresentam probabilidade ainda menor de encontrar um doador nos registros citados.

Com o propósito de aliviar a dificuldade de encurtar o tempo para se identificar um doador de medula óssea não familiar, compatível, Rubinstein et al., em 1993, estabeleceram o primeiro banco de células de SCUP, no New York Blood Center (NYBC), com a colaboração do National Heart, Lung and Blood Institute (NHLBI). A criação do programa se iniciou em meados de 1990, a primeira coleta e armazenamento ocorreu em fevereiro de 1993 e, em junho do mesmo ano, quando havia cerca de 300 unidades estocadas, foram identificados dois doadores para pacientes da Duke University, que foram submetidos aos transplantes, respectivamente em agosto e setembro de $1993^{(49,50)}$.

Desde então, vários programas semelhantes se desenvolveram, tanto na América do Norte quanto na Europa (EUROCORD), inclusive com a criação de redes internacionais de cooperação, contribuindo para a normatização de procedimentos e a uniformização de resultados (NETCORD) ${ }^{(51 / 54)}$. A situação, no Brasil, é semelhante quanto à necessidade de regulamentação e criação de uma rede de bancos de sangue de cordão umbilical (BRASILCORD), apesar das dificuldades financeiras inerentes à situação econômica do país, especialmente para a implantação de novas tecnologias na área da saúde, aspecto que será abordado com mais detalhes no final desta revisão (Secção 6.6.).

\subsection{Vantagens e Desvantagens do SCUP}

O SCUP tem muitas vantagens teóricas em relação à medula óssea, como fonte de $\mathrm{CPH}$, sendo uma das principais, a relativa imaturidade destas células no recém-nascido. Assim, em comparação com as células adultas, os precursores hematopoéticos do SCUP 
estão enriquecidos com elementos mais primitivos, que dão origem in vivo às células responsáveis pela repopulação hematopoética a longo prazo. As células tronco do SCUP dão origem a grandes colônias, na presença de fatores de crescimento, e apresentam necessidades peculiares destes, na presença dos quais, as culturas in vitro de longa duração (LTC-IC ou long term culture-initiating cell) fornecem elevado número de células progenitoras hematopoéticas. São células capazes de promover enxertia em camundongos radicalmente imunodeficientes ( $S C I D$ mice), até mesmo na ausência de fatores de crescimento. Além disto, seus telômeros são maiores do que os das células adultas, o que, em conjunto com as outras propriedades mencionadas acima, conferem às CHP do SCUP uma vantagem proliferativa em relação às células adultas e devem compensar sua relativa deficiência numérica, quando se comparam as unidades de SICUP com as de medula óssea ou sangue periférico. Assim, através da expansão dessa população celular in vitro, deverá ser possível, no futuro, obter reconstituição hematopoética, tanto de crianças quanto de adultos, após tratamento mieloablativo ${ }^{(55)}$.
Uma segunda vantagem do SCUP está relacionada com a relativa imaturidade do sistema imune ao nascimento. Na Tabela XI, descrevemos as principais diferenças dos linfócitos do SCUP, quando comparados com os dos adultos. Os linfócitos T do SCUP possuem um fenótipo imaturo, enriquecido de células virgens (CD45RA+RO-) e CD3+ duplo, negativas para CD4 e CD8, produzem menos citocinas e expressam RNA mensageiro para interferon gama, IL-4 e IL10 , mas muito pouco para IL 2, o que indica a predominância de um padrão Th2, imunorregulador. O repertório de células $\mathrm{T}$ está completo e pode ser protegido de apoptose devido aos baixos níveis de CD95 ${ }^{(56,57)}$. As funções das células NK também estão reduzidas, porém a maioria delas pode ser ativada in vitro ou in vivo. Em conseqüência, a citotoxicidade das células T e NK estão inicialmente prejudicadas, porém sujeitas a ativação secundária.

Com base nessas observações, podemos postular que o transplante de SCUP induz DECH aguda com menor freqüência e de menor gravidade do que o transplante de CHP adultas, em se tratando de um evento precoce pós-TMO e mediado por células T

\begin{tabular}{|c|c|c|}
\hline & Sangue Adulto & SCUP \\
\hline \multirow[t]{2}{*}{ Células T } & $\%$ CD45RO+ > CD45RA+ & CD45RA > CD45RO \\
\hline & 介CD3+CD4 +ou CD8+ & $\Uparrow \mathrm{CD} 3+\mathrm{CD} 4-\mathrm{CD} 8-$ \\
\hline Alorreatividade & Produção de Interferon-gama & Baixa produção de INF-gama \\
\hline Estimulação mitogênica de células $T$ & $\begin{array}{l}\text { Produção de TNF-alfa, INF- gama e } \\
\text { IL-10 }\end{array}$ & Baixa produção destes fatores \\
\hline Repertório de células T & Policlonal e oligoclonal & $\begin{array}{l}\text { Estritamente policlonal e constituição } \\
\text { plena }\end{array}$ \\
\hline Produção de citocinas intracelulares & $\begin{array}{l}\text { Células T produzem citocinas do } \\
\text { tipo Th1 }\end{array}$ & $\begin{array}{l}\text { Células } T \text { têm habilidade de amadurecer } \\
\text { até cels. do tipo Th2 produtoras de IL-10 }\end{array}$ \\
\hline Efeito do soro & Estimula proliferação de células $T$ & Sem efeito na proliferação de céls $T$ \\
\hline Função NK & Expressão de CD57 & Sem expressão de CD57 \\
\hline \multirow[t]{2}{*}{ Apoptose } & \multirow{2}{*}{$\begin{array}{l}\text { Expressão de CD95 (Fas) e CD95L } \\
\text { (Fa< ligante) }\end{array}$} & Reduzida expressão de CD95 \\
\hline & & Sem expressão de CD95L \\
\hline Moléculas de HLA Classe II & Peptídeo carregado & $\begin{array}{l}\text { Alto nível de moléculas de HLA Classe II } \\
\text { vazias em células B }\end{array}$ \\
\hline \multicolumn{3}{|l|}{ Adaptado de Madrigal e col (ref. 56) } \\
\hline
\end{tabular}


maduras e citocinas ${ }^{(56)}$. No entanto, pela presença de precursores de células T e NK no SCUP, não haveria prejuízo quanto ao efeito enxerto-contra-leucemia (ECL ou $G V L)$. Estas propriedades permitem uma maior flexibilidade quanto aos critérios imunogenéticos de seleção de doadores utilizados nos transplantes de SCUP.

Dentre as principais vantagens práticas do SCUP, estão: a facilidade relativa na pesquisa de doadores, já que as unidades estão armazenadas, a ausência de riscos para as mães e recém nascidos, a reduzida probabilidade de transmissão de infecções, particularmente do CMV, e a habilidade do produto ser armazenado e criopreservado, com os testes e tipagens HLA completamente realizados, o que garante disponibilidade para uso imediato. Inicialmente, estas vantagens foram descritas com o SCUP de doadores aparentados. Mais recentemente, a padronização de procedimentos como coleta, identificação, registro, processamento, criopreservação, busca de doadores e transporte foi desenvolvida em vários centros visando a uniformidade que possibilita a troca entre os centros, de unidades de SCUP para transplante não aparentado ${ }^{(49,50,58)}$.

Atualmente (Março/2000), cerca de 43000 unidades de SCUP se encontram armazenadas em todo o mundo, sendo o principal inventário o do NY Blood Center, com 8000 unidades, seguido da Espanha com 5500 unidades disponíveis. Estes números vêm crescendo rapidamente, principalmente pela criação de organizações sem fins lucrativos, como o NETCORD, dedicada ao estabelecimento de critérios de qualificação e credenciamento de Bancos de SCUP. Seus propósitos incluem, além da criação de uma rede internacional de Bancos para facilitar as pesquisas de doadores, a garantia de que as unidades oferecidas tenham controle de qualidade rigoroso em múltiplos aspectos, desde a viabilidade celular até a ausência de anormalidades genéticas.

Desde o primeiro transplante realizado em um paciente com anemia de Fanconi em 1988 por Gluckman et al. ${ }^{(59)}$, mais de 1000 casos foram relatados em todo o mundo. A análise destes resultados clínicos demonstra que o transplante de SCUP aparentado é superior ao não aparentado em algumas, mas não em todas as indicações (vide abaixo). Os fatores associados com sobrevida melhor em transplante de SCUP aparentado e não aparentado são menor idade, diagnóstico de erros inatos do metabolismo e de leucemia aguda em primeira e segunda remissão. $\mathrm{O}$ número de células nucleadas na unidade transplantada e receptor com sorologia negativa para CMV também foram fatores favoráveis para sobrevida ${ }^{(51,60)}$.
Algumas possíveis desvantagens do SCUP como fonte de células progenitoras para transplante, em comparação com medula óssea ou sangue periférico de adultos, seriam: 1) a existência de infecções, causadas por agentes conhecidos, como o HIV e os vírus das hepatites $\mathrm{B}$ e $\mathrm{C}$, não diagnosticados se a coleta for realizada durante a "janela imunológica", ou camadas por agentes desconhecidos, não detectados no sangue de cordão pelos testes atualmente disponíveis; 2) a presença de doenças genéticas não diagnosticadas que se manifestam apenas mais tardiamente. Estes obstáculos têm sido superados através de um adequado questionário aplicado às mães, testes para diagnóstico materno e no sangue coletado, manutenção das unidades em quarentena por pelo menos três meses e consulta acompanhada de exames do recém-nascido e da mãe de três a seis meses após a doação. Além destes cuidados, as amostras são armazenadas para avaliação futura em caso de surgirem novos agentes ou testes obrigatórios ${ }^{(61 / 63)}$.

\subsection{Seleção de Doadores, Coleta e Armazena- mento do SCUP}

São considerados candidatos a doação de SCUP os recém nascidos de partos que satisfaçam pelos menos as condições mínimas de segurança, que são: 1) filhos de gestantes com 18 a 36 anos que tenham sido submetidas a pelo menos duas consultas de pré-natal documentadas; 2) idade gestacional acima de 35 semanas e trabalho de parto sem anormalidades, 3) ausência de processos infecciosos e de história familiar de doença genética que possa afetar o receptor, 4) preenchimento de extenso questionário que avaliará a história pregressa e familiar e de termo de consentimento informado, permitindo a inclusão da unidade de SCUP no inventário do Banco. Além destes cuidados, a unidade de SCUP somente será incorporada ao Banco e liberada para transplante após a realização de exame médico e testes laboratoriais na criança e na mãe pelo menos 3 a 6 meses após a doação ${ }^{(58)}$.

Em relação ao procedimento de coleta, este pode ser realizado por vários métodos, como: 1$)$ drenagem espontânea do sangue pela, extremidade distal do cordão seccionado para um becker contendo anticoagulante e, em seguida, acondicionamento em bolsas para processamento; ou 2) cateterismo venoso umbilical, com conexão direta com a bolsa de processamento contendo anticoagulante, no momento em que a placenta ainda se encontra intraútero, aproveitando a própria contração uterina; ou ainda 3) após a retirada da placenta, realizando-se a coleta sem qualquer interferência com o parto. Na maioria dos centros, o 
procedimento fechado e a coleta após a expulsão da placenta (3) tem sido o mais utilizado e considerado de maior segurança ${ }^{(51,58)}$.

Após a coleta, a identificação, armazenamento e transporte devem ser cuidadosos a fim de não comprometer a qualidade do produto. Cabe ressaltar a necessidade de total confidencialidade da origem da unidade de SCUP, estando a identificação restrita a códigos de conhecimento apenas dos profissionais envolvidos com a coordenação dos Bancos.

Os testes realizados na unidade de SCUP incluem a triagem para doenças infecciosas, tipagem HLA-A, -B e -DR por técnicas moleculares de baixa resolução e tipagem sanguínea $\mathrm{ABO}$ e Rh. Os testes no sangue materno são realizados até 48 horas após o parto. Além desta rigorosa avaliação, somente serão aceitas unidades com volume superior a $70 \mathrm{ml}$, contagens para avaliação de celularidade, incluindo obrigatoriamente contagem de $\mathrm{CPH} \mathrm{CD} 34+$ por citometria de fluxo ou fluorimetria de microvolume, teste de viabilidade e quantificação de células formadoras de colônias hematopoéticas (CFU-GM). Em geral, recomenda-se que apenas sejam armazenadas unidades de SICUP com contagem igual ou superior a $5 \times 10^{8}$ células nucleadas.

O processo de criopreservação mais utilizado submete a unidade ao congelamento sob taxa de resfriamento programado em equipamento adequado, após a manipulação para retirada das hemácias e redução do volume. As unidades de SCUP são mantidas em reservatórios de nitrogênio líquido a temperaturas de $-150^{\circ} \mathrm{C}^{(51,58)}$.

\subsection{Resultados de transplantes de SCUP apa- rentado}

O primeiro transplante de SCUP foi realizado em 1988 em um paciente com anemia de Fanconi utilizando sangue de cordão de seu irmão saudável coletado e criopreservado ao nascimento. O regime de condicionamento consistiu de baixas doses de ciclofosfamida e irradiação linfóide, a recuperação hematopoética do paciente foi rápida, não ocorreu $\mathrm{DECH}$ e o paciente encontra-se atualmente em completa reconstituição hematológica e imunológica com células do doador ${ }^{(59)}$.

Desde então, vários centros passaram a coletar e armazenar SCUP de famílias que apresentavam uma criança portadora de uma afecção potencialmente curável pelo transplante de $\mathrm{CPH}$. Em recente publicação, a experiência foi analisada, consistindo de 102 pacientes submetidos a transplantes com
SCUP aparentado entre outubro de 1988 e janeiro de 1998. O tempo mediano de acompanhamento foi de 30 meses (variação de 0.1-111), a idade mediana de 5 anos (variação de 0.2-20) e o peso mediano de $19 \mathrm{~kg}$ (variação de 5-50). Quanto às indicações, 61 pacientes tinham doença maligna (LLA, LMA, LMC, SMD, neuroblastoma, linfoma não-Hodgkin) e 41 pacientes apresentavam doença não-maligna (anemia aplástica, hemoglobinopatias, erros inatos do metabolismo). Em 80 casos, o doador era HLA-idêntico e, em 22 casos, parcialmente idêntico. O número mediano de células nucleadas infundidas foi de $4,0 \times 10^{7} / \mathrm{kg}$ (variação de $\left.0,7-18 \times 10^{7}\right)$. A recuperação de granulócitos ocorreu em média no $28^{\circ}$ dia e a de plaquetas, no $48^{\circ}$ dia. Dez pacientes faleceram antes dos 60 dias pós-TMO e 18 pacientes não apresentaram "pega" do enxerto. A sobrevida em um ano foi de $64 \% \pm 5 \%$, com diferença significativa favorecendo o grupo que recebeu transplante HLA-idêntico $(73 \% \text { contra } 30 \%)^{(51)}$.

Da experiência acima relatada, podemos concluir que os resultados com SCUP de irmãos idênticos são comparáveis aos de medula óssea, mas estudos comparativos futuros devem ser realizados. No grupo de pacientes que receberam SCUP parcialmente compatível, pode ser observada uma correlação entre o número de incompatibilidades na tipagem HLA e a incidência de DECH.

\subsection{Resultados de transplantes com SCUP não aparentado $^{(60 / 62)}$}

Até maio de 2000, cerca de 562 transplantes de SCUP não aparentado foram proporcionados pelo inventário do NYBC e 216 pelo EUROCORD e seus bancos afiliados. Em sua maioria ( $82 \%$ ), foram beneficiados pacientes com menos de 18 anos.

Rebulla e col.(comunicação pessoal), reportaram a experiência de Milão, no período de fevereiro de 1995 a dezembro de 1999, com 75 pacientes beneficiados com sobrevida de um ano de $44 \%$, no grupo que recebeu SCUP HLA-idêntico, de $36 \%$ com um antígeno HLA diferente e de $49 \%$ com dois antígenos diferentes. Quanto à recuperação do enxerto, $84 \%$ dos pacientes evoluíram com "pega" e as principais causas de óbitos foram $\mathrm{DECH}$, recaída da doença básica e infecção.

Em abril de 1998, foram publicados os resultados de 158 transplantes não aparentados de SCUP pelo EUROCORD $^{(54)}$. Os pacientes eram 102 crianças e 44 adultos, portadores de malignidades diversas e afecções não malignas. A sobrevida global em um ano dos pacientes na faixa etária pediátrica foi de $35 \% \pm$ 
6\% e alguns fatores que contribuíram com melhor sobrevida foram status CMV negativo antes do transplante e compatibilidade $\mathrm{ABO}$. A recuperação de granulócitos ocorreu em $74 \%$ dos casos e a incidência de DECH agudo grau $\geq$ II foi de $38 \%$. Quanto aos receptores adultos, a sobrevida global foi de $16 \% \pm 6 \%$ e a maioria dos pacientes recebeu menos do que $3 \mathrm{x}$ $10^{7} / \mathrm{kg}$ células nucleadas. O número de células infundidas e o estágio da doença inicial influíram significativamente no prognóstico.

Estes resultados mostram que os transplantes de SCUP não aparentados oferecem resultados positivos nas crianças, principalmente nas portadoras de leucemias agudas, erros inatos de metabolismo ou imunodeficiências. Os resultados em adultos e em pacientes com anemia aplástica ainda devem ser melhorados. A incompatibilidade HLA não é um obstáculo, porém o número de células nucleadas $/ \mathrm{kg}$ infundidas certamente influencia os resultados.

Algumas questões ainda permanecem em dis- cussão, incluindo os critérios de escolha do doador, as indicações de transplante de SCUP em crianças e adultos, a comparação com outras fontes de $\mathrm{CPH}$ e o papel dos fatores de crescimento de expansão celular a fim de acelerar e garantir a recuperação e manutenção do enxerto a curto e longo prazo.

Com os conhecimentos acumulados até o momento, podemos sugerir como estratégia prática de abordagem do paciente que necessita de um transplante de CPH, e que não possui um doador aparentado, o fluxograma mostrado na Figura 2, o qual engloba o uso de SCUP. A decisão final sobre qual tipo de transplante selecionar (aparentado ou não, de medula óssea ou de cordão umbilical, HLA-idêntico ou não) depende de vários fatores, como a natureza e progressão da doença básica, as condições clínicas do paciente, o tempo necessário para identificar o doador e determinantes logísticos e econômicos envolvidos na coleta das células $^{(64)}$. (Vide Capítulo VII na $2^{\text {a }}$ parte do Simpósio).

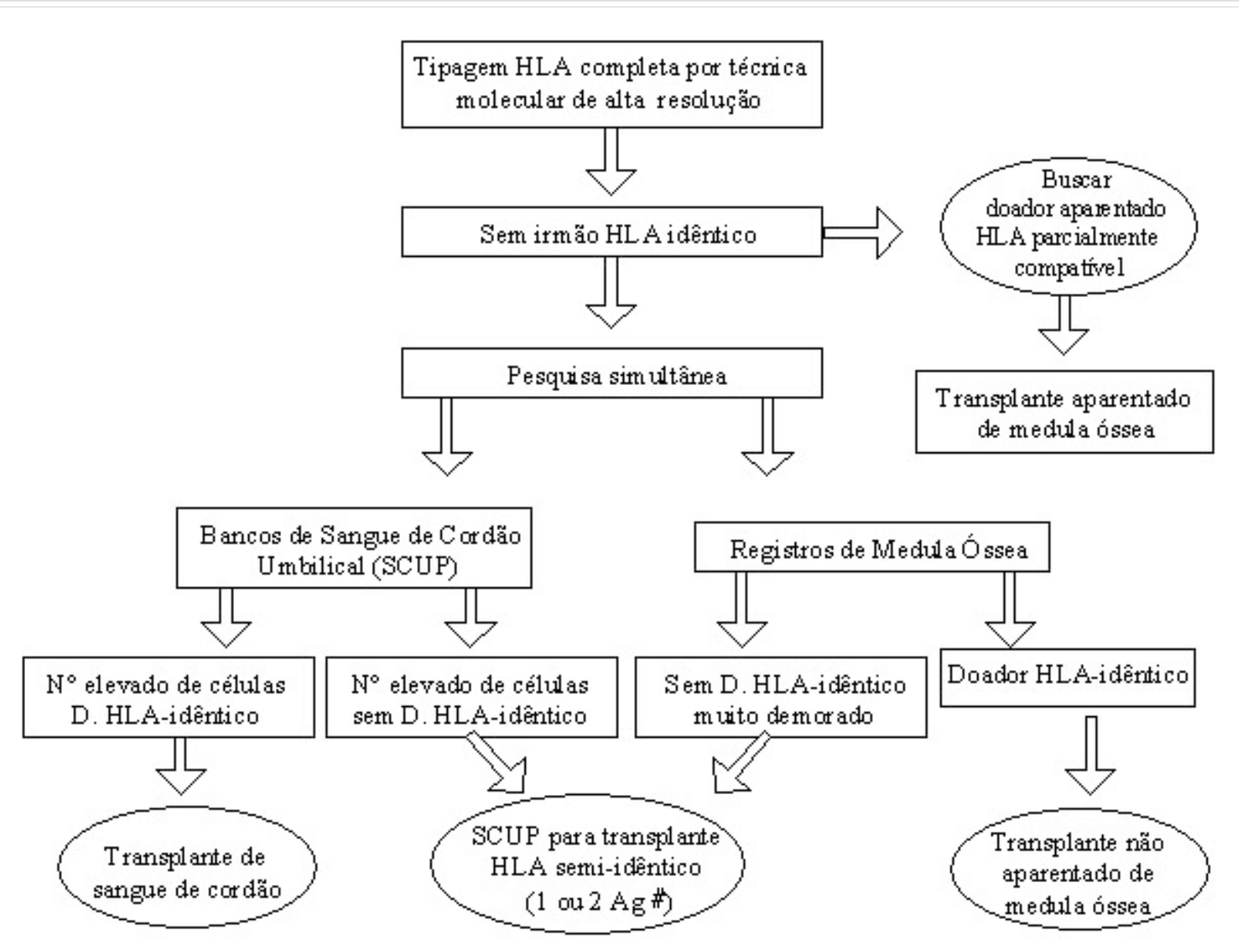

Figura 2: Estratégia prática para a pesquisa de um doador alternativo de células progenitoras hematopoéticas. D: Doador 
6.6 Situação nacional do transplante de cordão umbilical e criação do BRASILCORD

No CEMO/INCA, cerca de 40 unidades de SCUP aparentado foram criopreservadas desde 1992, sendo apenas uma utilizada até o momento, em uma criança com 2 anos de idade e $12 \mathrm{~kg}$ de peso, portadora de leucemia mielóide crônica, que foi transplantada em 1996 com o SCUP de seu irmão HLA-idêntico. Apresentou reação aguda ao DMSO contido no SCUP (bradicardia e hipotensão reversíveis), "pega" de neutrófilos no dia +35 e de plaquetas no dia +45 , com quimerismo documentado por PCR. A criança evoluiu sem DECH e recaiu 11 meses após a infusão do SCUP, sendo submetida a TMO proveniente do mesmo doador, falecendo do dia +30 por toxicidade do condicionamento (BU/CY nas duas situações) e infecção.

De acordo com a comunicação pessoal de
Hamerschlak e col., no Hospital Albert Einstein em São Paulo, foram armazenadas 17 unidades de SCUP, sendo realizados até o momento sete transplantes incluindo um autogênico. Já no Hospital de Clínicas de Curitiba, foram criopreservados até agora 93 unidades de SCUP e foram realizados, a partir de 1993, 15 transplantes (10 aparentados e 5 não aparentados). As características clínicas e a evolução de 14 destes transplantes estão reunidas na Tabela XII. Verifica-se uma baixa frequência e gravidade de DECH aguda e crônica, mas uma alta frequência de falha de enxertia $(6 / 14)$, contribuindo para a mortalidade $(50 \%)$, predominantemente de causas infecciosas, não mostradas na Tabela. No presente ano, foi realizado mais um transplante de cordão umbilical, não-aparentado (com 2 antígenos HLA-incompatíveis), em uma criança com anemia de Fanconi, utilizando um regime de condicionamento não-mieloablativo (fludarabina + ICT 200cGy).

\begin{tabular}{|c|c|c|c|c|c|c|c|c|}
\hline Doença básica & $\begin{array}{l}\text { Idade } \\
\text { anos }\end{array}$ & Doador HLA & $\begin{array}{c}\text { № cels. } \\
10^{7} / \mathrm{kg}\end{array}$ & Pega & $\begin{array}{l}\text { GVHD } \\
\text { agudo }\end{array}$ & $\begin{array}{l}\text { GVHD } \\
\text { crônico }\end{array}$ & Recaída & $\begin{array}{l}\text { Estado } \\
\text { atual }\end{array}$ \\
\hline LMA & 3 & $\mathrm{Irm}=$ & 0,82 & Compl & 0 & Extenso & Não & Vivo \\
\hline LMA & 8 & $\mathrm{Irm}=$ & 1,19 & Compl & 0 & 0 & Sim & Óbito \\
\hline LLA & 5 & $\mathrm{Irm}=$ & 0,32 & Não & 0 & 0 & Não & Óbito \\
\hline LMC & 26 & $N R \neq-A$ & 0,17 & Não & 0 & 0 & Não & Óbito \\
\hline LMCj & 1 & $\operatorname{Ir}=$ & 0,44 & Compl & 0 & 0 & Não & Vivo \\
\hline Fanconi & 12 & $\mathrm{Ir}=$ & 0,39 & Não & 0 & 0 & Não & Óbito \\
\hline SMD & 2 & $N R \neq-B$ & 8,4 & Não & 0 & 0 & Sim & Óbito \\
\hline LMA & 2 & $\operatorname{lr}=$ & 0,9 & Compl & 0 & 0 & Não & Vivo \\
\hline S.Kostmann & 1 & $\neq-B$ & 0,32 & Não & III & 0 & Não & Óbito \\
\hline MDS & 3 & $\neq-B$ & 1,19 & Compl & 0 & Limit. & Não & Vivo \\
\hline SCID & 1 & $\operatorname{lr}=$ & 7,3 & Compl & II & 0 & Não & Vivo \\
\hline LLA & 2 & $\mathrm{Ir}=$ & 3,46 & Compl & 0 & 0 & Sim & Óbito \\
\hline LMC & 9 & $\mathrm{Fr}$ & 0,51 & Compl & 0 & 0 & Sim & Vivo \\
\hline LMA & 1 & $N R \neq A$ & 1,98 & Não & 0 & 0 & $?$ & Vivo \\
\hline
\end{tabular}


Houve recuperação hematopoética completa no D+35 os estudos de quimerismo mostraram $100 \%$ de células do doador e, presentemente, 3 meses após o transplante, a paciente se encontra em bom estado, do ponto de vista clínico e hamatológico (Pasquini, comunicação pessoal).

Diante das dificuldades já citadas no sentido de se obter CPH para transplantes alogênicos entre não aparentados no Brasil, tanto pela ausência de representatividade étnica adequada nos registros internacionais, quanto pelo tamanho ainda reduzido do "pool" de doadores do Registro Brasileiro de Doadores de Medula Óssea (REDOME), que se encontra em fase de reestruturação, surgiram vários centros interessados na constituição de Bancos de SCUP.

Numa primeira oportunidade, houve uma reunião durante o encontro da Sociedade Brasileira de Transplante de Medula Óssea (SBTMO) realizado em julho de 1999, seguido de várias outras reuniões de trabalho com a participação de representantes das principais unidades interessadas no assunto (listadas na Tabela XIII). Surgiu a opção, considerada mais compa-

\begin{tabular}{|c|c|}
\hline \multirow[t]{2}{*}{ Alfredo Mendrone JR. } & Hemocentro de São Paulo \\
\hline & Hospital de Clínicas de São Paulo \\
\hline \multirow[t]{2}{*}{ Algemir L. Brunetto } & Instituto de Câncer Infantil \\
\hline & Rio Grande do Sul \\
\hline \multirow[t]{2}{*}{ Dimas T. Covas } & Hemocentro de Ribeirão Preto \\
\hline & Hospital das Clínicas de Ribeirão Preto \\
\hline \multirow[t]{2}{*}{ Giorgio Roberto Baldanzi } & Seção de Hemoterapia \\
\hline & Hospital das Clínicas da UFPR \\
\hline Hélio M. Souza & Coordenadoria de Sangue Hemoderivados Min. da Saúde \\
\hline \multirow[t]{2}{*}{ Jorge Neumann } & Laboratório de Imunologia de Transplantes \\
\hline & Santa Casa de Porto Alegre \\
\hline \multirow[t]{2}{*}{ Luis Fernando S. Bouzas } & Centro de Transplante de Medula Óssea \\
\hline & Instituto Nacional de Câncer - MS \\
\hline \multirow[t]{2}{*}{ Marcelo T. A. Veiga } & Seção de Hemoterapia \\
\hline & Hospital das Clínicas da UFPR \\
\hline \multirow[t]{2}{*}{ Marco Antônio Zago } & Hemocentro de Ribeirão Preto \\
\hline & Colégio Brasileiro de Hematologia \\
\hline Nelson Hamerschlack & Hospital Albert Einstein de São Paulo \\
\hline Pedro Clóvis Junqueira & Sociedade Brasileira de Hematologia e Hemoterapia \\
\hline \multirow[t]{2}{*}{ Ricardo Pasquini } & Unidade de Transplantes de Medula Óssea \\
\hline & Hospital das Clínicas da UFPR \\
\hline \multirow[t]{2}{*}{ Sara T. A. Saad } & Hemocentro de Campinas \\
\hline & Fac. Ciências Médicas da UNICAMP \\
\hline \multirow[t]{2}{*}{ Vanderson Rocha } & Projeto EuroCord \\
\hline & Hôpital Saint Louis, Paris, França \\
\hline
\end{tabular}


tível com a situação nacional, de se criar uma rede coordenada de bancos de sangue de cordão umbilical, denominada provisoriamente BRASILCORD. Esta rede tem por objetivo concentrar esforços no sentido de aproveitar em parte a estrutura e competência técnica já disponível, sem criar pressão insuportável em um único centro, mantendo a viabilidade econômica, normatizando todo o processo e propiciando melhor alocação de recursos.

Trata-se de uma organização ainda em fase embrionária, porém com objetivos claros de utilização ade- quada dos recursos atualmente disponíveis e busca de novas fontes de manutenção para um empreendimento de suma importância para o nosso país. Por outro lado, com a normatização dos bancos de sangue de cordão, será possível a implantação de um sistema de qualidade e certificação que garantirá a atuação dos serviços envolvidos com esse procedimento, tanto no cenário nacional, quanto no internacional. Estará, assim, criada, em nosso país, a estrutura para viabilizar a aplicação sistemática de um novo tipo de TCPH em nosso meio, previsto há mais de dez anos ${ }^{(64)}$.

BOUZAS LFS. Bone marrow transplantation in children and cord blood transplantation. Medicina, Ribeirão Preto 241-263, july/sept. 2000.

ABSTRACTS: Bone marrow transplantation has been used in children for treatment of an increasing number of malignant and benign hematological diseases and of solid tumors. The source of bone marrow for transplantation in most cases is an allogenic donor including related HLA-identical, related one HLA antigen mismatch, non-related HLA-identical or, in rare instances, related with 2 or 3 HLA mismatches. Cells from placenta and cord blood (PCB) have also been considered for related or unrelated allogenic transplantation with promising results. Factors like the relative feasibility of collection, flexibility in regards to HLA compatibility between patients and donors and the possibility of storage in cell banks contribute to the development of cord blood transplantation. Most patients treated for solid tumors receive autologous transplantation from bone marrow or peripheral blood. Complications of transplantation still include early or late toxicity from conditioning regimens, acute or chronic graft-versus-host disease, infections, prolonged immnunodeficiency and relapse of initial disease. Prolongation of survival of transplanted patients, specially in the pediatric population, raises concern about late complications that worsen the results, including poor quality of life, crippling organic and neuropsychosocial disabilities. Ongoing research conducted in this field will contribute continuosly to reduce post-transplant complications, increasing survival, both quantitatively and qualitatively.

UNITERMS: Bone Marrow Transplantation. Umbilical Cord . Pediatrics. Cell Transplantation.

\section{REFERÊNCIAS BIBLIOGRAFICAS}

1 - ANASETTI C ;HOWE C; PETERSDORF EW; MARTIN PJ \& HANSEN JA.Marrow transplants from HLA-matched unrelated donors: An NMDP update and Seattle experience. Bone Marrow Transplant 13:693-695, 1994.

2 - BALDUZZI A; GOOLEY T; ANASETTI C; SANDERS JE; APPELBAUN FR; MARTIN PJ; PETERDORF ER; BUCKNER CD; MATTHEWS D; STORB R; SULLIVAN KM \& HANSEN JA. Unrelated donor marrow tranasplantation in children. Blood 86: 3247-3256, 1995.

3 - BARRET AJ; HOROWITZMM; POLLOCK BH;ZHANG MJ;BORTIN MM; BUCHNAN GR; CAMITTA BC; OCHS J; GRAHAM-POLE J; ROWLING PA; RIMMAA; KLEIN JP; SHUSTER JJ ; SOBOCINSKI KA \& GDE RP. . Bone marrow transplants from HLA- identical siblings as compared with chemotherapy for children with acute lymphoblastic leukemia in a second remission. $\mathbf{N}$ Engl $\mathbf{J}$ Med 331: 1253-1258, 1994.
4 - BENSINGER WI; LONGIN K; APPELBAUM F; ROWLEY S; WEAVER C; LILLESBY K; GOOLEY T; LYNCH M; HIGANO T; KLARNET J; CHAUNCEYT;STORB R \& BUCKNER CD. Peripheral blood stem cells (PBSCs) collected after recombinant granulocyte colony-stimulating factor (rhG-CSF): An analysis of factors correlating with the tempo of engraftment after transplantation. Br J Haematol 87: 825 -831, 1994.

5 - BENSINGER WI, WEAVER CH, APPELBAUM FR; ROWLEY S; DEMIRER T; SANDERS J; STORB R \& BUCKNER CD.Transplantation of allogeneic peripheral blood stem cells mobilized by recombinant human granulocyte colony-stimulating factor. Blood 85: 1655-1658, 1995.

6 - BILLET AL; KORNMEHL E; TARBELL NJ; WEINSTEINHJ; GEBBER RD; RITZ J \& SALLAN SE. : Autologous bone marrow transplantation after a long first remission for children with recurrent acute lynphoblastic leukemia. Blood 81: 1651-1657,1993.

7 - SCHMITZ N; GRATWOHL A \& GOLDMAN JM. Allogeneic and autologous transplantation for haematological diseases, solid 
tumours and immune disorders: current practice in Europe in 1996 and proposals for na operational classification. Bone Marrow Transplant 17: 471-477, 1996.

8 - GOLDMAN JM; SCHMITZ N; NIETHAMMER D \& GRATWOHLA. Allogeneic and autologous transplantation for haematological diseases, solid tumors and immune disorders: current practice in Europe in 1998. Bone Marrow Transplant 21: 1-7, 1998.

9 - BLUME KG; FORMAN SJ; O'DONNELL MR; DOROSHOW JH; KRANCE RA; NADEMANEE AP; SNYDER DS; SCHMIDT GM; FAHEY JL; METTER GE; HILL LR; FINDLEY DO \& SNIECINSKI IJ. Total body irradiation and high-dose etoposide: A new preparatory regimen for bone marrow transplantation in patients with advanced hematologic malignancies. Blood 69: 10151020, 1987.

10 - KALIFA C; HARTMANN O; DEMEOCQ F; VASSAL G; COUNET D; TERRIER LACOMBE MJ; VALTEAU D; BRUGIERES L \& LEMERLE J. High-dose busulfan and thiotepa with autologous bone marrow transplantation in childhood malignant brain tumors: A phase II study. Bone Marrow Transplant 9: 227233, 1992.

11 - PETERSEN FB;APPELBAUM FR; BIGELOW CL; BUCKNER CD; CLIFTRA; SANDERS JE; SULLIVAN KM; WEIDEN PL \& FEFER A. High-dose cytosine arabinoside, total body irradiation and marrow transplantation for advanced malignant lymphoma. Bone Marrow Transplant 4: 483-488,1989.

12 - COCCIA PF; STRANDJORD SE; WARKENTIN PI; CHEUNG NK; GORDON EM; NOVAK LJ; SHINADC \& HERZIG RH. High-dose cytosine arabiniside and fractioneted total-body irradiation: Am improved preparative regimen for bone marrow transplantation of children with acute lymphoblastic leukemia im remission. Blood 71: 888-893, 1988.

13 - COLLESELLI P; DINI G; ANDOLINA M; BONETTI F; MINIERO R; SONEGO M; PIGOZZO P; MESSINA C; PORTA F \& SCOTTI G. Autologous bone marrow tranplantation for acute lynphoblastic leukemia; The high dose vincristine study of AIEOP BMT group. Bone Marrow Transplant 7: 28-30,1991, (suppl 3).

14 - SEEGER RC; VILLABLANCA JG; MATTHAY KK; HARRIS R; MOSS TJ; FEIG SA; SELCH M; RAMSAY N \& REYNOLDS CP. Intensive chemoradiotherapy and autologous bone marrow transplantation for poor prognosis neuroblastoma. Progr Clin Biol Res 366: 527-533, 1991.

15 - STRAM DO, MATTHAY KK, O'LEARYM; REYNOLDS CP; HAASE GM; ATKINSON JB; BRODEUR GM \& SEEGER RC. Consolidation chemoradiotherapy and autologous bone marrow transplantation versus continued chemotherapy for metastatic neuroblastoma: A report of two concurrent Children's Cancer Group studies. J Clin Oncol 14: 2417-2426, 1996.

16 - THOMAS ED; BUCKNER CD; BANAJI M; CLIFT RA; FEFER A; FLOURNOY N; GOODELL BW; HICKMAN RO; LERNER KG; NEIMAN PE; SALE GE; SANDERS JE; SINGER J; STEVENS M; STORB R \& WEIDEN PL. One hundred patients with acute leukemia treated by chemotherapy, total body irradiation, and allogeneic marrow transplantation. Blood 49: 511-533, 1977.

17 - SULLIVAN KM; AGURAE; ANASETTI C; APPELBAUM F; BADGER C; BEARMAN S; ERICKSON K; FLOWERS M; HANSEN J \& LOUGHRAN T. Chronic graft-versus-host disease and other late complications of bone marrow transplantation. Semin Hematol 28: 250-259,1991.
18 - FORMAN SJ; BLUME KG; KRANCE RA; MINER PJ; METTER GE; HILL LR; O'DONNELL MR; NADEMANEE AP \& SNYDER DS. A prospective randomized study of acute graft-v-host disease in 107 patients with leukemia: Methotrexate/prednisone v cyclosporine A/prednisone. Transplant Proc 19: 2605-2607, 1987.

19 - MARTINPJ; HANSENJA; TOROK-STORB B; MORETTIL; PRESS O; STORB R; THOMAS ED; WEIDEN PL \& VITETTA ES. Effects of treating marrow with a CD3-specific immunotoxin for prevention of acute graft-versus-host disease. Bone Marrow Transplant 3: 437-444, 1988.

20 - STORB R; DEEG HJ; PEPE M; APPELBAUM F; ANASETTI C; BEATTY P; BENSINGER W; BERENSON R; BUCKNER CD; CLEIFT R; DONEY K; LONGTON G; HANSEN J; HILL R; LOUGHRAN T; MARTIN P. SINGER J; SANDERS J, STEWART P; SULLIVANK; WITHERSPOONR\& THOMAS ED. Methotrexate and cyclosporine versus cyclosporine alone for prophylaxis of graft-versus-host disease in patients given HLA-identical marrow grafts for leukemia: Long-term follow-up of a controlled trial. Blood 73: 1729- 1734, 1989.

21 - SANDERS JE. Bone marrow transplantation for pediatric malignancies. Pediatr Clin North Am 44: 1005-1020,1997.

22 - RIEHM H; GADNER H; HENZE G; KORNHUBER B; LAMPERT F; NIETHAMMER D; REITER A \& SCHELLONG G. Results and significance of six randomized trials in four consecutive ALLBFM studies (review). Hematol Bluttransfus 33: 439-450, 1990.

23 - BLUME KG; FORMAN SJ; SNYDER DS; NADEMANEE AP O'DONNELL MR; FAHEY JL; KRANCE RA; SNIECINSKI IJ; STOCK AD; FINDLEY DO; LIPSETT JA; SCHMIDT GM; NATHWAM MB; HILL LR \& METTERS GE. Allogeneic bone marrow transplantationfor acute lymphoblastic leukemia during first complete remission. Transplantation 43:389-392, 1987.

24 - BORDIGONI P; VERNANT JP; SOUILLET G; GLUCKMAN E; MARININCHID; MILPIED N; FISCHER A; LEMOINE EB; JOUET JP \& REIFFERS J. Allogeneic bone marrow transplantation for children with acute lymphoblastic leukemia in first remission: A cooperative study of the group d'etude de la greffe de moelle osseuse. J Clin Oncol 7:747 - 753, 1989.

25 - CHAO NJ; FORMAN SJ; SCHMIDT GM; SNYDER5 DS; AMYLON MA; KONRAD PN; NADEMANEE AP; O'donnell RO; PARKER PM; STEIN AS; SMITH E; WONG RM ; HOPPE RT \& BLUME KG. Allogeneic bone marrow transplantation for high-risk acute lymphoblastic leukemia during first complete remission. Blood 78: 1923 -1927, 1991.

26 - BROCHSTEIN JA; KERMAN NA; GROSHEN S;CIRRINCIONE C; SHANK B; EMMANUEL D; LAVER J \& O'REILLY RJ. Allogeneic bone marrow transplantation after hyperfractioned total-body irradiation and cyclophosphamide in children with acute leukemia. N Engl J Med 317: 1618-1624, 1987.

27 - DOPFER R; HENZE G; BENDER-GÖTZE C; EBELL W; EHNINGER G; FRIEDRICH W; GARDNER H; KLINGEBIEL T; PETERS C; RIEHM H; SUTTORP M; SCHMITZ N; SIEGERT W; STOLLMAN-GIBBELS B; HARTMANN R \& NIETHAMMER D. Allogeneic bone marrow transplantation for childhood acute lymphoblastic leukemia in second remission after intensive primary and relapse therapy according to the BFM- and CoALL protocols: Results of the German Cooperative Study. Blood 78: $2780-2784,1991$. 
28 - SANDERS JE; THOMAS ED; BUCKNER CD \& DONEY K. Marrow transplantation for children with acute lymphoblastic leukemia in second remission (concise report). Blood 70: 324326, 1987.

29 - WOODS WG; NESBIT ME; RAMSAY NKC; KRIVIT W; KIM TH GOLDMAN A; McGLAVE PB \& KERSEY JH. Intensive therapy followed by bone marrow transplantation for patients with acute lymphocytic leukemia in second or subsequent remission: Determination of prognostic factors (a report from the University of Minnesota Bone Marrow Transplantation Team). Blood 61: 1182-1189, 1983.

30 - HERVE P; LABOPIN M; PLOUVIER E; PALUT P; TIBERGHIENP \& GORIN N. Autologous bone marrow transplantation for childhood acute myeloid leukemia: A European survey. Bone Marrow Transplant 8: 76-79, 1991.

31 - SANTOS GW; TUTSCHKA PJ; BROOKMEYER R; SARAL R; BESCHORNER W; BRAS WB; BRAINE HG; BURNS WH; ELFENBEIN GJ; KAIZER H; MELLITS D; SENSENHENNER LL; STUART RK \& YEAGER AM. Marrow transplantation for acute nonlymphocytic leukemia after treatment with busulfan and cyclophosphamide. N Engl J Med 309: 1347-1353, 1983

32 - CREUTZIG U; RITTER J \& SCHELLONG G: Identification of two risk groups in childhood acute myelogenous leukemia after therapy intensification in study AML-BFM-83 as compared with study AML-BFM-78. Blood 75: 1932-1940, 1990

33 - WEINSTEIN HJ; MAYER RJ; ROSENTHAL DS; CORAL FS; CARMITTA BM \& GELBER RD. Chemotherapy for acute mYelogenous leukemia in children and adults: VAPA update. Blood 62: 315-319, 1983

34 - WELLS RJ; WOODS WG; BUCKLEY JD;ODOM L; BENJAMIN D; BERNSTEINI; BETCHEND; FEIG S; KIMTAE; RUYMANN F; SMITHSON W; SRIVASTAVAA; TANNOUS R; BUCKLEY CM. WHITT K; WOLFF L \& LAMPKIN BC. Treatment of newly diagnosed children and adolescents with acute myeloid leukemia: a Children's Cancer Group Study. J Clin Oncol 12:23672377, 1994

35 - WOODS WG; KOBRINSKY N; BUCKLEY J ; LEE JW; SANDERS J; NEUDORF S; GOLD S; BARBARD DR; DeSWARTE J; DUSENBERY K; KALOUSEKI D; ARTHUR DC \& LANGE BJ. Timed-sequential induction therapy improves postremission outcome in acute myeloid leukemia: A report from the Children's Cancer Group. Blood 87: 4979-4989, 1989.

36 - THOMAS ED \& CLIFT RA. Indications for marrow transplantation in chronic myelogenous leukemia. Blood 73: 861-864, 1989.

37 - CLIFT RA \& STORB R. Marrow tranplantation fo CML: The Seattle experience. Bone Marrow Transplant 17: S1-S3, 1996

38 - LOCATELLI F; NIEMEYER C;ANGELUCCI E; BENDER-GOTZE C;BURDACH S; EBELL W; FRIEDRICHW; HASLE H; HERMANN J; JACOBSEN N; KLINGEBIEL T; KREMENS B; MANN G; PESSIAN A; PETERS C; SCHMID HJ; STARY J; SUTTORP M; UDERZO C; VAN'T VEER-KORTHOF E; VASSEN J; ZECCAMJ \& ZIMMERMANN M. and Members of the European Working Group on Myelodysplastic Syndrome in childhood: Allogeneic bone marrow transplantation for chronic myelomonocytic leukemia in childhood: A report from the European Working Group in Myelodispastic Syndrome in Childhood. J Clin Oncol 15:566-573, 1997
39 - ODONE V. Transplantes autólogos de medula óssea em oncologia pediátrica- experiência preliminar do Instituto da Criança Prof. Pedro de Alcântara, do Hospital das Clínicas da Faculdade de Medicina da Universidade de São Paulo (ICR). J Pediatria 72: 209-214, 1996

40 - KHAYAT D; GIROUX B; BERILLE J; COUR V; GERARD B; SARKANY M; BERTRAND P \& BIZZARI JP. Fotemustine in the treatment of brain primary tumors and metastases. Cancer Invest 12: 414-420, 1994.

41 - LUM LG; MUNN NA; SCHANFIELD MS \& STORB R: The deyection of specific antibody formation to recall antigens after human bone marrow transplantation. Blood 67: 582587,1986

42 - BORDALLO MAN; BOUZAS LF; TAVARES RCB; LERNER D \& TABAK DG. Impacto da quimioterapia na função gonadal de crianças e adolescentes submetidos a transplante de medula óssea. Série de Monografias da Escola Brasileira de Hematologia 6: 26, 1999. Suppl. 1.

43 - SANDERS JE; HAWLEY J; LEVY W; GOOLEY T; BUCKNER CD; DEIG J; DORNEY K; STORB R; SULLIVAN K; WITHERSPOON R \& APPELBAUM FR. Pregnancies following high-dose cyclophosphamide with or without high-dose busulfan or total-body irradiation and bone marrow transplantation. Blood 87: 3045-3052, 1996

44 - BOUZAS LF; TAVARES RB; LERNER D; LIMA MG; MATTAJ; BYINGTON R; LOBO A; COLARES M; SILVA MLM \& TABAK D. Pregnancies following different preparative regimens for Bone Marrow Transplantation (BMT). Blood 94 : 331a, 1999. Suppl.1.

45 - LIMA MG; BONAMINO M; VASCONCELOS Z; BOUZAS LF; DIAMOND H; ZALCBERG I; ANDRADE C; BOUZAS L; MATTA J; TAVARES R; LERNER D; BYINGTON R; SILVA M; CARVALHO L; PIRES V; BARONE B; MACIEL C \& TABAK D. Moderately ablative chemotherapy, hematopoietic stem cell transplantation (HST) and prophylatic donor lymphocyte infusions (DLI) for poor prognosis patients (PTS) with hematological malignancies. Blood 94349 a, 1999. Suppl.1.

46 - HANSEN JA; PETERSDORF E, MARTIN PJ \& ANASETTI C. Hematopoietic stem cell transplants from unrelated donors. Immunol Rev 157:141-151 1997.

47 - SPEISER DE; TIERCY JM; RUFER N; GRUNDSCHOBER C; GRATWOHLA; CHAPEURS B; HELG C; LOLIGEN CC; SIREN MK; ROOSNE KE \& JEANNET M. High resolution HLA matching associated with decreased mortality after unrelated bone marrow transplantation. Blood 10: 4455-4462, 1996.

48 - MADRIGAL JÁ; SCOTT I; ARGUELLO R \& SCYDLO R. Factors influencing the outcome of bone marrow transplants using unrelated donors. Immunol Rev 157:153, 1997.

49 - RUBINSTEIN P; ROSENFIELD RD; ADAMSON JW \& STEVENS CE. Stored placental blood for unrelated bone marrow reconstitution. Blood 81: 1679, 1993.

50 - RUBINSTEIN P; DOBRILA L; ROSENFIELD REI; ADAMSON JW; MIGLIACCIO G; MIGLIACCIO AR;TAYLOR PE \& STEVENS CE. Processing and cryopreservation of placental/umbilical cord blood for unrelated bone marrow reconstitution. Proc Natl Acad Sci USA 92: 10119-10122,1995. 
51 - GLUCKMAN E; ROCHA V; CHASTANG CL. ON BEHALF OF EUROCORD-CORD BLOOD TRANSPLANT GROUP. Cord blood hematopoietic stem cells biology and transplantation. In: Meeting. Educational Program of tha American Society, p. 114, dec. 1998..

52 - CAIRO MS \& WAGNER JE. Placental and/or umbilical cord blood: An alternative source of hematopoietic stem cells for transplantation. Blood 90: 4665,1997

53 - ROCHA V; CHASTANG CL; SOUILLET G et al for the Eurocord transplant group. Related cord blood transplants: The Eurocord experience of 78 transplants. Bone Marrow Transplant 21: S 59, 1998. Suppl. 3.

54 - GLUCKMAN E; ROCHA V \& CHASTANG C. European results of unrelated cord blood transplants. Bone Marrow Transplant 21: S 87, 1998. Suppl. 3.

55 - BROXMEYER HE; HANGOC G; COOPER S; RIBEIRO RC; GRAVES V; YODER M; WAGNER J; VADHAN-RAY S; BENNINGER L; RUBINSTEIN P \& BROUN ER. Growth characteristics and expansion of human umbilical cord blood and estimation of its potential for transplantation in adults. Proc Natl Acad Sci USA 89: 4109-4113, 1992.

56 - MADRIGAL JA; COHEN SBA; GLUCKMAN E \& CHARRON DJ. Does cord blood transplantation result in lower graft versus host disease? It takes more than two to tango. Human Immunol 56: 1-5 1997.

57 - GARDERET L, DULPHY N, DOUAY C; CHALUMEAU HI; SCHAEFFEN V; ZILBER MT.; LIM A.; EVEN J; MOONEY N; GELIN C; GEUCKMAN E; CHARION D \& TOUBERT A. The umbilical cord Blood alfa beta $T$ cell repertoire: Characteristics of a polyclonal and naive but completely formed repertoire. Blood 91: 340-346, 1998.

58 - FRASER JK; CAIRO MS; WAGNER EL; MCCURBY PR; BAXTER-LOWE LA; CARTER SL; KERNAN NA; LILL MC; SLONE V; WAGNER JE; WALLAS CH \& KURTZBERG J. Cord Blood Transplantation Study (COBLT): Cord Blood Bank Standard Operating Procedures. J Hematotherl 7: 521-561, 1998.
59 - GLUCKMAN E; BROXMEYER HE; AUERBACH AD; FRIEDMAN HS; DOUGLAS GW; DEVERGIE A; ESPEROU H; THIERRY D; SOCIE G; LEHN P; COOPER S; ENGLISH D; KURTZBERG J BARD J \& BOYSE EA.. Hematopoietic reconstitution in apatient with Fanconi"s Anemia by means of umbilical cord blood from an HLA-identical sibling. N Engl J Med 321: 11741178,1989

60 - GLUCKMAN E; ROCHA V; BOYER-CNAMMARD A; LOCATELLI F; ARCESE W; PASQUINI R; ORTEGA J; SOUILLET G; FERREIRAE; LAPORTE JP; FERNANDEZ M \& CHASTANG C. Outcome of cord blood transplantation from related and unrelated donors. N Engl J Med 337: 373-381, 1997

61 - KURTZBERG J; LAUGHLIN M; GRAHAM; SMITH C; OLSON JE; HALPERIN EC; CLOCCI G; CARRIER C; STEVENS CE \& RUBINSTEIN P. Placental blood as a source of hematopoietic stem cells for transplantation into unrelated recipients. N Engl J Med 335: 157-166, 1996.

62 - WAGNER JE; ROSENTHAL J; SWEETMAN R; SHU XO; DAVIES SM; RAMSAY NI C; MCGLAVE PB; SENDER L \& CAICO M \& CAIRO MS. Successful transplantation of HLA matched and HLA mismatched umbilical cord blood from unrelated donors: Analysis of engraftment and acute graft versus host disease. Blood 88: 795-802, 1996.

63 - BURGIO GR \& LOCATELLI F. Transplant of bone marrow and cord blood hematopoietic stem cells in pediatric practice, revisited according to fundamental principles of bioethics. Bone Marrow Transplant 19: 1163-1168, 1997.

64 - BROXMEYER HE; GORDON GW; HANGOC G; COOPER S; BARD J; ENGLISH D; ARNY M; THOMAS L \& BAOYSE EA Human umbilical cord bood as a potential source of transplantable hematopoietic stem/progenitor cells. Proc Natl Acad Sci USA 86: 3828-3832, 1989.

Recebido para publicacao em 13/06/2000

Aprovado para publicacao em 11/07/2000 